\title{
Options Study Documenting the Fast Reactor Fuels Innovative Design Activity
}

Jon Carmack

Kemal Pasamehmetoglu

July 2010

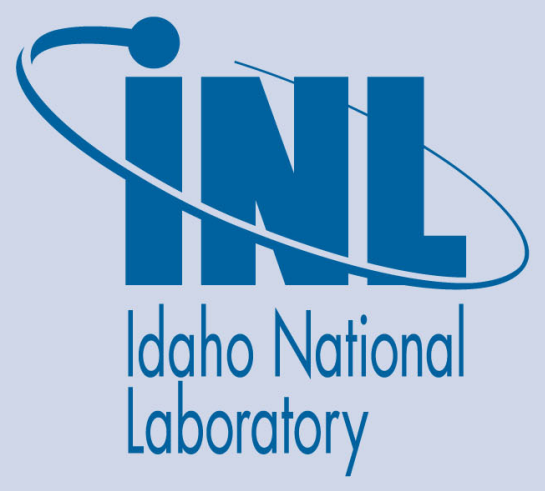

The INL is a U.S. Department of Energy National Laboratory operated by Battelle Energy Alliance 
INL/EXT-10-19999

FCRD-FUEL-2010-000108

\title{
Options Study Documenting the Fast Reactor Fuels Innovative Design Activity
}

\author{
Jon Carmack \\ Kemal Pasamehmetoglu \\ July 2010 \\ Idaho National Laboratory \\ Fuel Cycle Research \& Development \\ Fuels Campaign \\ Idaho Falls, Idaho 83415 \\ htto://www.inl.gov \\ Prepared for the \\ U.S. Department of Energy \\ Office of Nuclear Energy \\ Under DOE Idaho Operations Office \\ Contract DE-AC07-05ID14517
}




\section{DISCLAIMER}

This information was prepared as an account of work sponsored by an agency of the U.S. Government. Neither the U.S. Government nor any agency thereof, nor any of their employees, makes any warranty, expressed or implied, or assumes any legal liability or responsibility for the accuracy, completeness, or usefulness, of any information, apparatus, product, or process disclosed, or represents that its use would not infringe privately owned rights. References herein to any specific commercial product, process, or service by trade name, trade mark, manufacturer, or otherwise, does not necessarily constitute or imply its endorsement, recommendation, or favoring by the U.S. Government or any agency thereof. The views and opinions of authors expressed herein do not necessarily state or reflect those of the U.S. Government or any agency thereof. 


\section{CONTENTS}

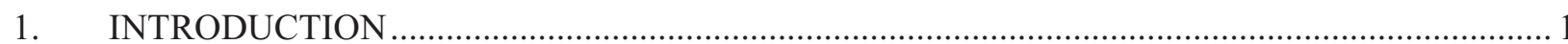

2. SUMMARY OF TOP THREE FUNDED PROPOSALS ….................................................... 2

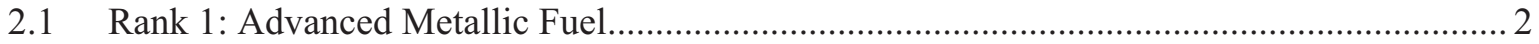

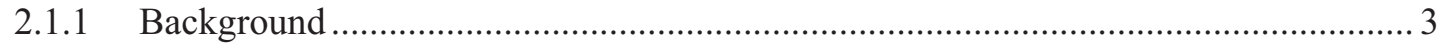

2.1.2 Advanced Fuel Concept Description and Benefits .................................................. 3

2.1.3 Advanced Reactor Concept Description and Benefits ............................................... 4

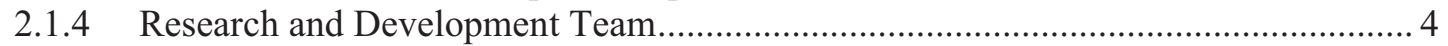

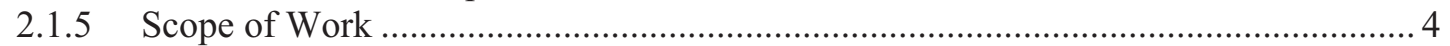

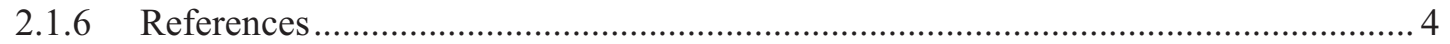

2.2 Rank 2: Vented Fuel Pellet/Getter Concept for High Burnup Fuel ........................................ 5

2.2.1 Description of Concept /Innovative Aspects............................................................. 5

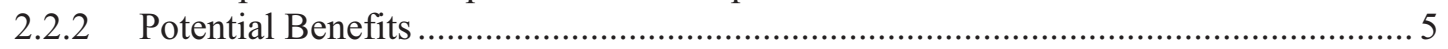

2.2.3 Research and Development / Team................................................................... 6

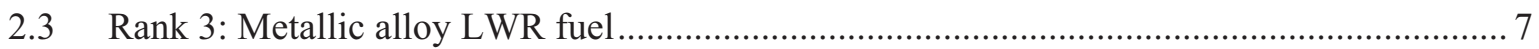

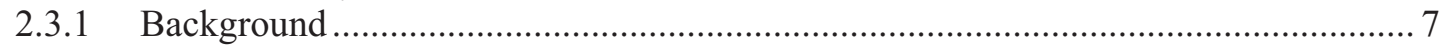

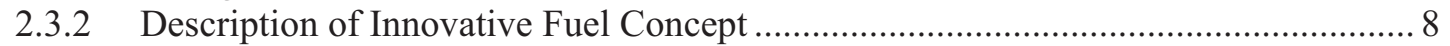

2.3.3 Scope of This Research and Development Proposal................................................ 8

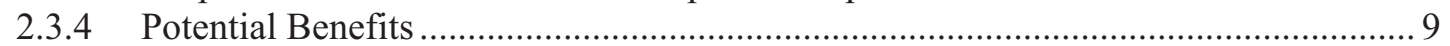

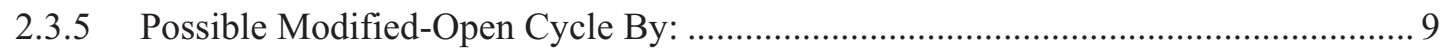

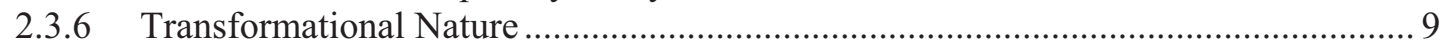

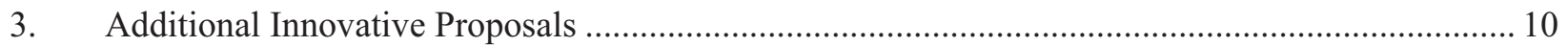

3.1 Rank 4: Innovative Transmutation Fuel Concept - Dispersion Fuel ................................... 11

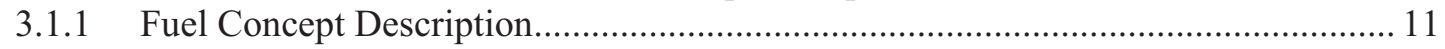

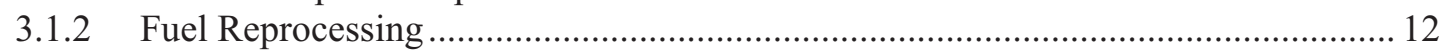

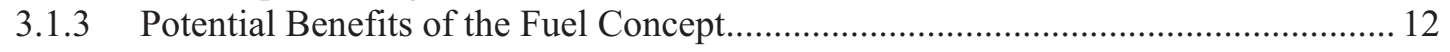

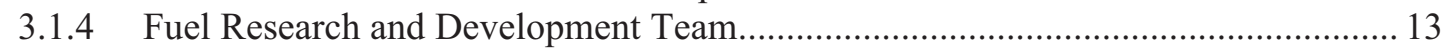

3.2 Rank 5: ULTRA-HIGH BURN-UP METALLIC INERT MATRIX NUCLEAR

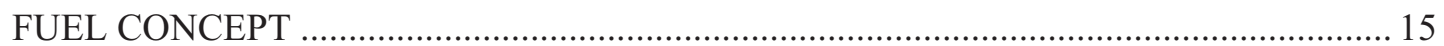

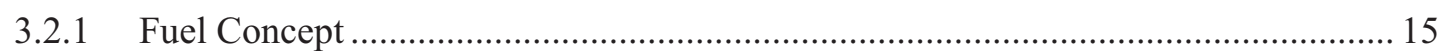

3.2.2 Innovative Approach to Fuel Performance ............................................................ 15

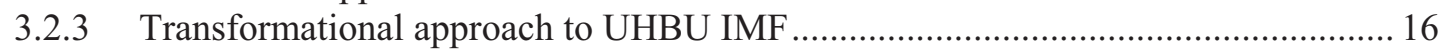

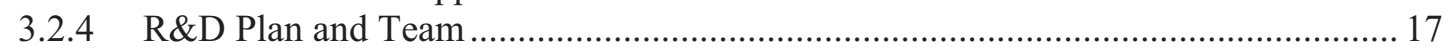

3.3 Rank 6: An Advanced High Integrity Gas Cooled Fast Reactor Fuel............................... 18

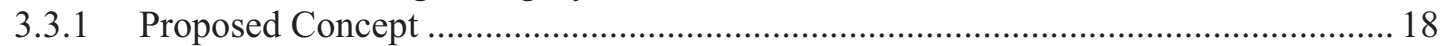

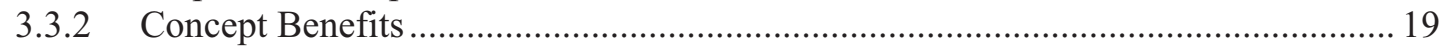

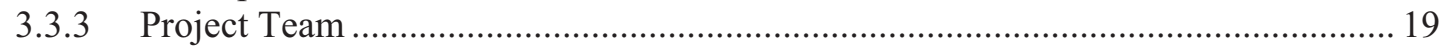

3.4 Rank 7: Multi-Layer Co-Extruded Metallic Fuel for Fast Reactors ................................... 21

3.4.1 Proposed Concept ....................................................................................... 21

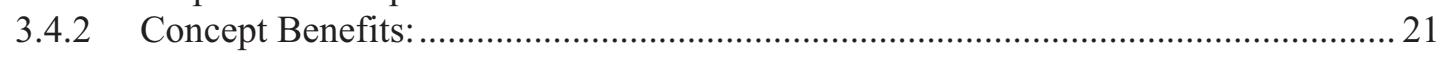

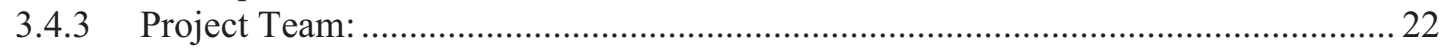

3.5 Rank 8: Enhanced Thermal Conductivity and Grain Boundary Engineering for

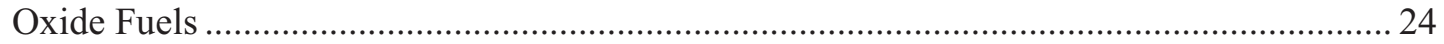

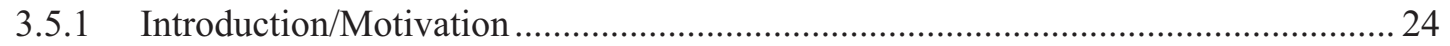

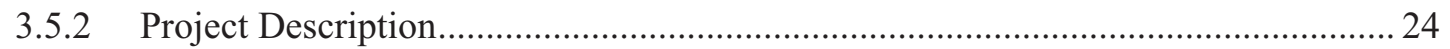

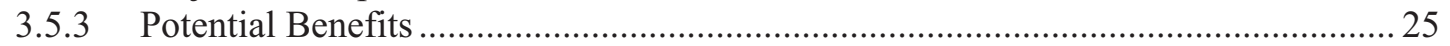




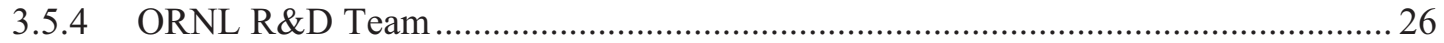

3.6 Rank 9: High Burn-Up Ceramic Composite Nuclear Fuels ............................................... 27

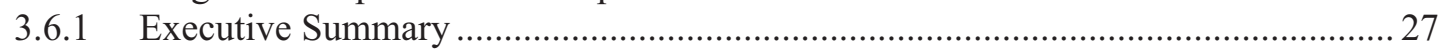

3.7 Special Selection: Thorium-Based Fuel Options for Thermal and Fast Reactors................. 31

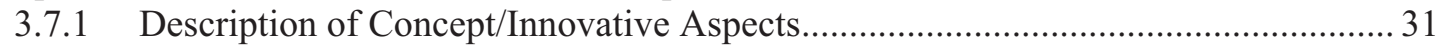

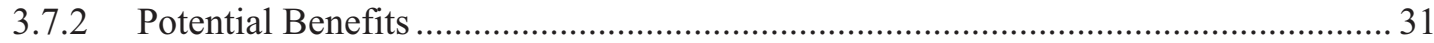

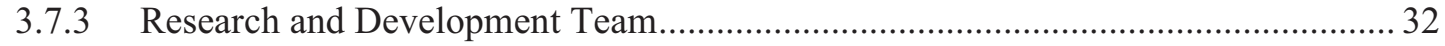

3.7.4 Thorium oxide fuel Concept Lead: Holly Trellue (LANL) ....................................... 33

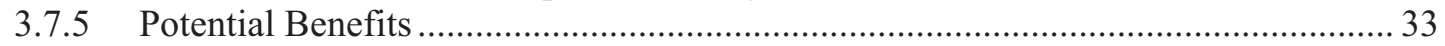

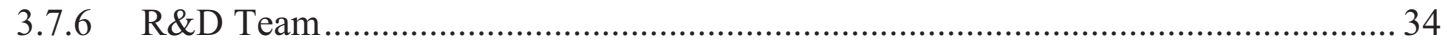

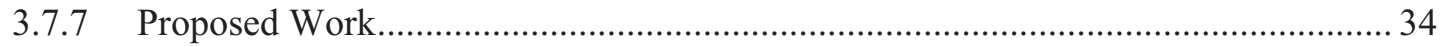

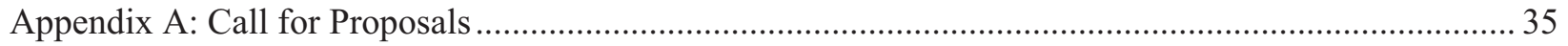

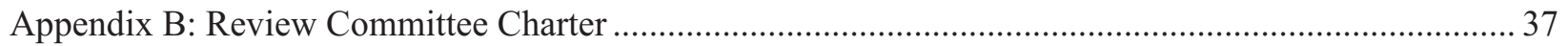




\section{OPTIONS STUDY DOCUMENTING THE FAST REACTOR FUELS INNOVATIVE DESIGN ACTIVITY}

\section{INTRODUCTION}

This document provides presentation and general analysis of innovative design concepts submitted to the FCRD Advanced Fuels Campaign by nine national laboratory teams as part of the Innovative Transmutation Fuels Concepts Call for Proposals issued on October 15, 2009 (Appendix A). Twenty one whitepapers were received and evaluated by an independent technical review committee. The list of submittals is provided in Table 1.

Table 1. Submitted Whitepapers.

\begin{tabular}{|l|l|l}
\hline Proposal Number & \multicolumn{1}{|c|}{ Organization } & Title \\
\hline INN-FUELS-001 & BNL & Throium-Based Fuel Options for Thermal and Fast Reactors \\
\hline INN-FUELS-002 & BNL & Water Reactor Concept Based on Direct Cooling of Particulate Fuel \\
\hline INN-FUELS-003 & BNL & Vented Fuel Pellet/Getter Concept for High Burnup Fuel \\
\hline INN-FUELS-004 & ANL/INL & Advanced Metallic Fuel Concept for Reliable Performance to Ultra-high burnup \\
\hline INN-FUELS-005 & INL & Dispersion Fuel \\
\hline INN-FUELS-006 & INL & Ultra high burnup spherical fuel element for actinide transmutation \\
\hline INN-FUELS-007 & LANL & Inert Am Target Development \\
\hline INN-FUELS-008 & LANL & Thoriurn 0xide fuel \\
\hline INN-FUELS-009 & LANL & High burn-up ceramic composite Nuclear Fuels \\
\hline INN-FUELS-010 & ORNL/INL & Extending Coated Particle Fuel Performance for Advanced Applications \\
\hline INN-FUELS-011 & ORNL & Enhanced Thermal Conductivity and Grain Boundary Engineering for Oxide Fuels \\
\hline INN-FUELS-012 & ORNL/LANL & Advanced Nitride Fuel Fabrication and Recycle \\
\hline INN-FUELS-013 & PNNL & Long-Lived Fission Product Transmutation Targets \\
\hline INN-FUELS-014 & PNNL & A Zoned Fuel Design to Achieve Very High Burnup in LWRs \\
\hline INN-FUELS-015 & PNNL & Uranium Alloy Metal Fuel for Light Water Reactors \\
\hline INN-FUELS-016 & SNL & Engineering Inert Matrix Fuels for High Burn-up \\
\hline INN-FUELS-017 & SNL & Expoiting the Properties of Nano-structured Materials for Innovative Nuclear Fuels Design \\
\hline INN-FUELS-018 & SNL/INL & Low Fabrication Losses by Near-Net Shaping of Sintered Nuclear Fuels \\
\hline INN-FUELS-019 & SRNL & A High Conductivity Light Water Reactor Fuel \\
\hline INN-FUELS-020 & SRNL & An Advanced High Integrity Gas Cooled Fast Reactor Fuel \\
\hline INN-FUELS-021 & SRNL & Multi-Layer Co-Extruded Metallic Fuel for Fast Reactors \\
\hline INN-FUELS-022 & LLNL & Ultra-high Burnup Metallic Inert Matrix Nuclear Fuel Concept \\
\hline
\end{tabular}

The review process provided a comprehensive review of each whitepaper concept. Six criteria were used by the review committee to evaluate the technical content and potential impact of each proposal.

1. Potential impact if successful and estimate of time to success

2. Burnup and performance capability

3. Efficient fabrication capability

4. Transmutation Capability and Fuel Cycle Impact

5. Identification of needed R\&D

6. R\&D Team capability

Review panel scores for each concept were sub-divided into three ranges;

High $(7,8,9)$ - a potential game changer that should be funded if at all possible

Medium $(4,5,6)$ - very innovative proposal that should be considered for funding 
Low $(1,2,3)$ - should not be considered for funding at this time

Each review committee member used a questionnaire to evaluate each concept. They then prioritized the list to identify their top-ten. In addition, they recommended partial scope opportunities and possible combinations of multiple concepts. Table 2 provides the relative ranking of the top 10 proposals that were recommended for some level of FY2010 funding. The results of the review and the individual panel evaluations have been archived and full documentation sent under previous cover to the Federal Technical Manager.

Table 2. Relative ranking of selected proposals, priority for FY2010 funding allotment and lead laboratory.

\begin{tabular}{|r|l|l|}
\hline$\#$ & Proposal & Lead Lab \\
\hline 1 & Advanced Metallic Fuel Concept for Reliable Performance to Ultra-high burnup & ANL/INL \\
\hline 2 & Vented Fuel Pellet/Getter Concept for High Burnup Fuel & BNL \\
\hline 3 & Uranium Alloy Metal Fuel for Light Water Reactors & PNNL \\
\hline 4 & Dispersion Fuel & INL \\
\hline 5 & Ultra-high Burnup Metallic Inert Matrix Nuclear Fuel Concept & LLNL \\
\hline 6 & An Advanced High Integrity Gas Cooled Fast Reactor Fuel & SRNL \\
\hline 7 & Multi-Layer Co-Extruded Metallic Fuel for Fast Reactors & SRNL \\
\hline 8 & Enhanced Thermal Conductivity and Grain Boundary Engineering for Oxide Fuels & ORNL \\
\hline 9 & High burn-up ceramic composite Nuclear Fuels & LANL \\
\hline 10 & Thorium Fuel Development Path Forward & BNL \\
\hline
\end{tabular}

\section{SUMMARY OF TOP THREE FUNDED PROPOSALS}

Each proposal selected for further funding by the FCRD Advanced Fuels Campaign is summarized below with overview of the concept.

\subsection{Rank 1: Advanced Metallic Fuel}

This paper summarizes a proposal for work to develop technology for an advanced metallic fuel concept in a sodium-cooled fast reactor (SFR). The goal is to develop a metallic-fueled SFR concept that achieves ultra-high burnup and does not require refueling. The fuel design features are based on extensions of known metallic fuel performance capabilities, supplemented by innovative fuel and reactor characteristics. The important components of the proposed work are 1) identification of fuel and reactor design features, and 2) assessment of fuel and reactor performance for confirmation of concept feasibility. 


\subsubsection{Background}

Metallic fuels have a history of use that spans the entire nuclear age, from the early plutonium production reactors (1940's) and the first liquid metal fast breeder reactors (1950's) to the most advanced reactor designs of today. Initially, metallic fuels were employed for their ease of fabrication and high heavy metal density (which led to the most favorable breeding efficiencies in fast reactors). During subsequent decades, metallic fuel technology matured significantly, leading to the realization of major benefits in fuel reliability and burnup, proliferation-resistant recycling, remote fabrication, and passive reactor safety. Such characteristics make metallic fuels a highly competitive technology, especially for use in sodium fast reactors. This unparalleled legacy notwithstanding, the proposed suite of design innovations promises to deliver multifold advances in fuel reliability and performance, actinide utilization, and fabrication efficiency, while retaining all the historic benefits of the metallic fuel system.

\subsubsection{Advanced Fuel Concept Description and Benefits}

The key features of the historic metallic fuel system are: 1) a metallic alloy fuel (U-Pu-Am-Np-Zr) at $75 \%$ smeared density to accommodate fuel swelling, 2) sodium-bonded to low-swelling ferriticmartensitic stainless steel cladding to keep fuel temperatures low, and 3) incorporating a large plenum to accommodate high gas release. The proposed innovations include:

- Decreased fuel smeared density. Further reduction of the fuel smeared density, to an appropriate level below $75 \%$, will allow for the accommodation of swelling to ultra-high burnups without cladding strain from fuel-cladding mechanical interaction. The reference path would retain the sodium bond. A proposed research path would investigate annular metallic fuel metallurgically bonded to the cladding, thus eliminating the sodium bond [1], leading to a smaller plenum volume and a reduction in waste hazard associated with sodium disposal.

- Coating or liner on cladding inner diameter. Use of a cladding coating or liner to act as a diffusion barrier will mitigate fuel-cladding chemical interaction [2].

- - Vented fuel pin. Venting the released fission gases and helium from the fuel pin into the primary reactor coolant will maintain cladding stresses at low levels to high burnup [1]. This innovation will also decrease plant capital cost due to a significant reduction in reactor vessel height.

- $\quad$ U-Mo based alloy fuel system. The uranium-zirconium based alloy fuel system suffers from phase separations in the composition and temperature ranges of interest. Those phase separations drive fuel constituent redistribution during irradiation, resulting in low-zirconium (and thus reduced solidus) regions within the fuel, which also promotes minor actinide and lanthanide migration. Transition to the uranium-molybdenum based alloy fuel system should eliminate this phenomenon and the safety concerns it raises and should also increase the fuel thermal conductivity and solidus temperature and possibly also improve the FCCI behavior. [3].

- $\quad$ Targeted fuel alloy additions. Major lanthanide fission products migrate to the fuel-cladding interface and react with the cladding, increasingly thinning the cladding and reducing its load-bearing capability. Targeted, minor alloy additions that will chemically bind with the lanthanides (and possibly minor actinides) and immobilize them have already been identified [4] and will be further investigated.

- Advanced fabrication method. Fabrication of the metallic fuel alloy by extrusion promises several benefits [5]: 1) 100\% utilization of each fuel ingot, dramatically reducing process waste; 2) elimination of volatile constituent losses during fabrication; and 3) co-extrusion of fuel and cladding in the annular fuel design.

- Fuel recycle. All of the proposed innovations retain complete compatibility with the historic electrochemical recycle scheme. 


\subsubsection{Advanced Reactor Concept Description and Benefits}

An ultra-long life core concept is proposed that targets capital and operational cost reductions in a sodium-cooled fast reactor system, while maintaining the capability to transmute actinides from LWR spent fuel. The core concept can be achieved by reducing the power density and optimizing core geometry to maintain adequate core power for more than 40 years without refueling. There are several benefits associated with operating the reactor without refueling during the reactor lifetime:

- Capital cost reduction. Elimination of refueling equipment reduces containment size requirements, and in-vessel fuel retention eliminates ex-vessel storage of irradiated fuel.

- Operating cost reduction. Elimination of in-core fuel management yields a higher capacity factor and simplifies heavy metal utilization.

- Low proliferation risk. The vessel is sealed and not opened during operation while effectively transmuting LWR spent fuel (in particular, $\mathrm{Pu}$ and minor actinides).

Such benefits cannot be achieved without an ultra-high burnup metallic fuel. Thus, the development of the proposed innovative fuel concept is critical for enabling the long life core. In addition, development of reliable core cooling methods, coolant purification methods, and innovative reactor control techniques are necessary. Fuel performance, reactor neutronics, fuel heat transfer, coolant hydraulics, and safety analyses are needed to confirm that the ultra-long life core can operate reliably and safely.

\subsubsection{Research and Development Team}

A team of highly experienced specialists from Argonne and Idaho National Laboratories has been assembled for this work. The team members are: J. E. Cahalan (project integration), Steven Hayes, Doug Porter and Eric Shaber (fuel design and fabrication), Gerard Hofman, Yeon S. Kim and Abdellatif M. Yacout (fuel design and performance), Taek K. Kim (reactor core neutronics design and analysis), Tanju Sofu (coolant chemistry, core thermal hydraulics, reactor safety).

\subsubsection{Scope of Work}

Following identification and prioritization of fuel design features, a reference metallic fuel design will be established, with provision for alternatives and options. Work will proceed to 1) specify fabrication technology, 2) analyze fuel irradiation performance, 3) analyze reactor physics performance, and 4) analyze reactor thermal, hydraulic, coolant chemistry, and safety performance. Analyses will focus on confirmation of fuel and reactor performance, fulfillment of long core life and high fuel burnup objectives, and identification of further needs for concept verification.

\subsubsection{References}

1. W. N. Beck, R. J. Fousek, and J. H. Kittel, "The Irradiation Behavior of High-Burnup UraniumPlutonium Alloy Prototype Fuel Elements," ANL-7388, May 1968. (See also B. Kryger, "Contribution a L'etude du Degagement des Gaz de Fission danes les Combustibles Nucleaires Metalliques," Rapport CEA-R-3888, October 1969).

2. J. I. Cole, R. Fielding, "Cladding Liner Development for GNEP Transmutation Fuels," Trans. Am. Nucl. Soc., Vol. 99 (2008) pp. 307-308.

3. Y.S. Kim, G.L. Hofman, A.M. Yacout, T.K. Kim, "An Assessment of the Use of U-Pu-Mo Fuel in Fast Reactors," International Conference on Fast Reactors and Related Fuel Cycles (FR09), Challenges and Opportunities - December 7 - 11, 2009, Kyoto, Japan, IAEA-CN-176.

4. Y.S. Kim, G.L. Hofman, A.M. Yacout, "Migration of Minor Actinides and Lanthanides in Fast Reactor Metallic Fuel,” J. Nucl. Matl., Vol. 392 (2009), pp. 164-170. 
5. R. Fielding, J. Jue, J. Stuart, "Zirconium Metal Inert Matrix Fuel Fabrication," Trans. Am. Nucl. Soc., Vol. 94 (2006) pp. 742-743.

\subsection{Rank 2: Vented Fuel Pellet/Getter Concept for High Burnup Fuel 2.2.1 Description of Concept /Innovative Aspects}

The proposed concept enables higher burnups for nuclear fuel by capturing the benefits of a vented fuel pin without its complications. The concept is intentionally designed to enhance fission gas release from the fuel pellet and sequester the gaseous fission products in the fuel's plenum. It is not restricted to LWR fuel, and as for the studies on vented fuel pins, can be extended to fast reactors or actinide burners. Elements of the proposed approach should be capable of being implemented in present LWR core configurations, and offer the potential of significantly reducing the fuel pin plenum size for high burnup fast reactor fuels.

The concept consists of two basic elements:

- A pellet fabrication technique employing fuel with nanoparticle as-fabricated grain size to enhance release of gaseous fission products, and have the potential for heterogeneous/zoned pellet enrichment.

- Use of a getter material located in the fuel plenum, which would sequester the gaseous fission products and thereby reduce the negative effects of their enhanced release from the fuel pellets (vented fuel pellets) and mitigate fuel failure modes. An effective getter could result in improved performance for all fuel forms, independent of whether or not the vented fuel pellet approach is employed.

\subsubsection{Potential Benefits}

Efforts to enhance burnup for nuclear fuel must overcome a number of obstacles. Not only must the fuel integrity be retained over the fuel cycle, but also it must be able to withstand anticipated transients and remain below the criteria set for design basis accidents. Advances have been made in dealing with the failure modes associated with fuel pellet clad mechanical and chemical interactions (PCMI/FCCI) associated with fuel swelling and clad stress corrosion cracking.

More recently, efforts have been expended on refining fuel performance models to more accurately predict the phenomena that occur in the fringe of the fuel pellet. This area is termed the High Burnup Structure (HBS). One phenomenon that occurs for certain types of fuels that exceed $75,000 \mathrm{MWD} / \mathrm{T}$ is a restructuring of the as-fabricated pellet material. Typically, the as-fabricated grain size of fuel pellets is about 10 microns. After the restructuring, the HBS has grain sizes on the order of $100 \mathrm{~nm}$.

One cause of the restructuring is related to the higher reaction rates that can occur at the pellet's outer surface. The consequences of the restructuring can be significant. The reduced grain size allows for greater fission gas release during operating conditions, and can amplify the gas release during transient conditions. It is well known that there are significant open feedback loop effects from the fission gas release, including higher pellet temperatures due to reduced gap conductivity. These effects may contribute to fuel failure, and must be addressed as we design fuels for higher burnups.

We propose a fuel design concept (Vented Pellet) to extend burnup that has these goals:

- Enhance fission gas release during normal operational conditions, and

- Employ a getter material in the plenum to significantly reduce the thermal, mechanical and other potential consequences of the enhanced fission gas release 


\subsubsection{Research and Development / Team}

To accomplish the first of these goals, we will reduce the as-fabricated pellet grain size to nanoparticle size. We will investigate fabrication techniques, including a variety of milling techniques, and alternative powder fabrication. The reduced grain size should enhance fission gas release and reduce pellet swelling. We would maintain the traditional $\sim 95 \%$ theoretical density of the fuel pellet.

Additionally we propose to investigate heterogeneously enriched fuel pellets; pellets with an internally higher enrichment than the exterior. The fabrication of the heterogeneous fuel pellets could be accomplished through various processing techniques. We propose this design to attenuate the fringe effect associated with the HBS phenomenon mentioned above. Furthermore, sol-gel technology has the benefit to reduce fabrication losses, especially those associated with powder processing.

The reduced pellet swelling should attenuate Pellet Clad Mechanical Interaction (PCMI/FCI). However, the gap conductance would be degraded by the enhanced gaseous fission product release unless the fission product gas is transported away from the active core power region. Our proposed concept would attempt to collect most of the fission product gases in a getter material located in a fuel pin plenum.

Initially focusing on present LWR technology, we will search for a getter material that will capture the typically standard gaseous fission products, (i.e., Krypton, Xenon), which represent about 13\% of the fission product yield spectrum.

We would research possible getter materials. The use of nanoporous carbon, and nanoparticles of carbon, possibly in fullerene form (nanotubes, bucky balls) will be studied. There have already been studies on the retention of noble gases by activated carbon, and on the capture of noble gases in the cage like structure of carbon fullerenes. Both empirical studies and molecular dynamic simulation has been used. Appropriate studies would be performed on the neutronic, thermal-mechanical, and overall fuel performance aspects of the proposed concept as they affect failure modes and safety criteria.

The R\&D team will consist of:

\begin{tabular}{|l|l|}
\hline Brookhaven National Laboratory: & John Valente (PI) \\
\hline University of Michigan: & Gary Was \\
\hline Los Alamos National Laboratory: & Carolynn Scherer \\
\hline
\end{tabular}

The R\&D needed with initial concept development being lead by BNL includes:

Heterogeneous pellet and pin (with plenum) neutronic analysis; Fuel performance code analysis (thermal - mechanical); Empirical studies on noble gas getter; Fabrication of fuel and getter material; Molecular dynamics studies on noble gas getter retention; and safety analysis. 


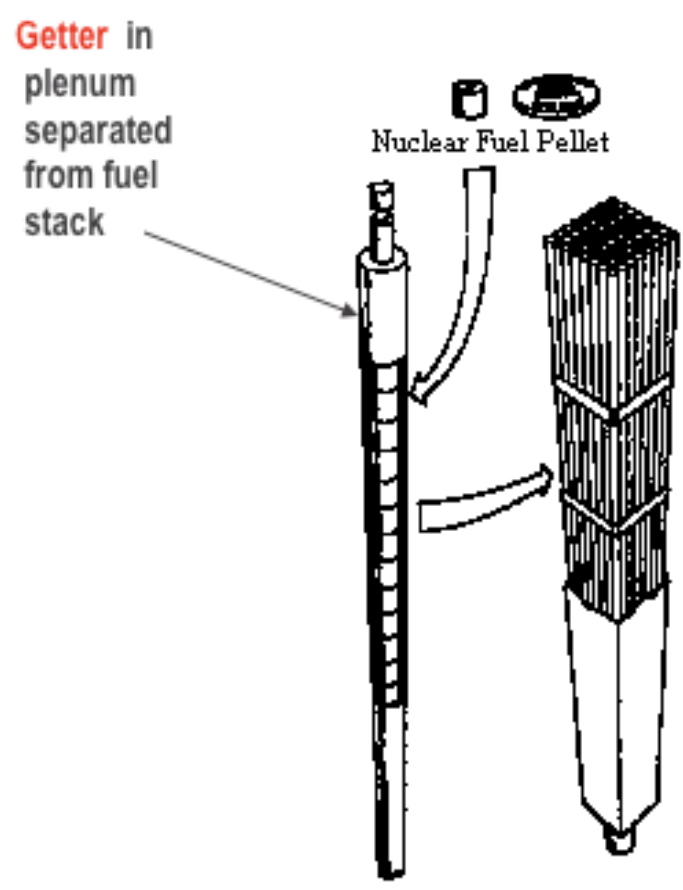

Figure 1. Schematic representation of vented/gettered fuel concept.

Brookhaven National Laboratory proposed the concept of enhancing fission gas release from the fuel pellet, transport, and sequestering the gases in the upper plenum region of the fuel rod.

\subsection{Rank 3: Metallic alloy LWR fuel}

The intent of this proposal is to develop and characterize a new, high density, heterogeneous, uranium alloy metal fuel for Light Water Reactors (LWR) that has the potential for substantially increasing linear heat rate and power density in a reactor while withstanding long term operations and severe accident conditions. It also has the possibility of opening a pathway to a Modified Open fuel cycle. The objective of this proposed effort would be to perform the research necessary to identify and characterize the novel, high density, heterogeneous, uranium alloy metal fuel for LWR and its potential impact on the overall US fuel cycle.

\subsubsection{Background}

Several different fuel types were considered for LWRs by the Atomic Energy Commission during the Power Reactor Demonstration Program. Decisions in this program led to the design and construction of the Yankee class of reactors (Maine Yankee, Connecticut Yankee, etc.) and to the selection of uranium oxide fuel. This decision was largely based on the lack of metal-water reactions in oxide fuels and the perceived ability to achieve a high burnup.

Later the consequences of a Large-Break Loss-of-Coolant Accident (LBLOCA), and the subsequent ability to cool the core, became more of a concern. This led to the Emergency Core Cooling System (ECCS) Hearings of the 1970s and subsequent changes to 10CFR50 with respect to Loss-of-Coolant Accidents (LOCA). Upon applying these requirements, the relatively low thermal conductivity of oxide fuel and its relative inability to reject heat became a limitation. This proposal will investigate a transformation to a new fuel system that will potentially eliminate or mitigate these limitations. 


\subsubsection{Description of Innovative Fuel Concept}

This proposal seeks to develop a heterogeneous metallic uranium alloy of high power density that contains a diffused surface layer for improved surface corrosion resistance. Materials being considered include uranium/molybdenum alloys with smaller quantities of niobium, aluminum, and/or chromium. A higher concentration of an alloy of niobium, aluminum, and/or chromium is solution heat treated and diffused into the outer surface of the uranium metal fuel rod for an integrated pliable outer layer that will withstand loading into the cladding during fabrication and provide superior corrosion resistance during accident scenarios. Several uranium metal alloys have been investigated over the last few decades and there is ample evidence that various metal fuel alloys can be developed that will significantly reduce swelling, metal-water reaction, and hydride formation. Molybdenum additions as small as 3\% inhibit phase transition with temperature that would normally result in swelling of unalloyed uranium metal ${ }^{(1)}$ References show that the addition of small amounts of niobium, zirconium, and/or aluminum to a U/Mo alloy could achieve reduced metal-water interactions ${ }^{(2)}$. Reviews of the literature indicate that small additions of aluminum may also be beneficial insofar as phase stability is concerned ${ }^{(3)}$.

The advantage and innovation associated with this concept is that the use of metal alloy fuel with a diffused outer protective layer will potentially allow a higher linear heat rate, higher power densities, potentially higher core power levels, and possibly improved accident response. The metal fuel fabrication process may have advantages with respect to fabricating transuranic fuel as it does not involve dealing with the powder associated with fabricating $\mathrm{UO}_{2}$ pellets. The used fuel could be reprocessed by pyrochemical processing means currently being developed for uranium metallic fuel. Furthermore, this transformational concept could potentially provide a pathway to a Modified Open fuel cycle in that the used fuel could be re-clad for further burning in a fast reactor without reprocessing. This concept will significantly change the status quo associated with LWR fuel in that it potentially opens the pathway to higher core power levels, larger safety margins, as well as the ability to fabricate fuel containing minor actinides without the radiological problems associated with conventional LWR pellet fuel.

\subsubsection{Scope of This Research and Development Proposal}

The scope of this proposal is to perform the research necessary to establish the basis for replacing the $\mathrm{UO}_{2}$ fuel in LWR with a heterogeneous uranium alloy fuel with a corrosion resistant, diffused outer surface on the uranium metal. This research in FY10 will produce a detailed conceptual design of the fuel, a process fabrication flow diagram, neutronic analyses, temperature and power performance predictions during routine and selected severe accident scenarios, and a recycle flow diagram including a fuel conditioning approach to support a modified open fuel cycle for subsequent burning in a fast reactor. A research plan will be developed to identify technical issues and means for resolving them over a multiyear program. Estimated costs for the first year of activities in FY10 are $\$ 350 \mathrm{~K}$.

The specific proposal in this white paper is to explore an array of metal alloys during the first year. The product will be a set of fuel meat alloys and diffused outer layers ranked in accordance with their ability of preclude the metal-water reaction, achieve phase stability, and achieve a high burnup. The ability to raise the core power as well as the response to the suite of Chapter 15 accidents will also be assessed.

The R\&D team for this initial first-year investigation will be based at the Pacific Northwest National Laboratory (PNNL) and will use expertise in this Laboratory derived from co-extruding N Reactor metal fuel and from developing the Tritium Target for use in LWRs. Quality Assurance requirements developed during the latter program will be employed. It is anticipated that university collaborators will be involved and that they will be Professor Donald Olander of the University of California at Berkeley along with Professor Lee Peddicord of Texas A\&M. These university collaborators will advise a research team consisting of: Curt Lavender who has developed co-extrusion and coating processes for uranium alloys, Ken Geelhood who is an expert on LWR fuel performance modeling for both steady state an transient conditions, including fuel rod LOCA response, Bruce Schmitt who is an expert on Chapter 15 accident assessment and LOCA modeling, Dr. Chuck Henager who is an expert on fuel performance 
including radiation effects, mechanical properties, and deformation, and Dr. Chris Gesh who is an expert on core reactor physics including the analysis of temperature and safety coefficients.

\subsubsection{Potential Benefits}

Possible Higher Linear Heat Rate and Core Power, Leading to Power Upgrades

Higher Core Conversion Ratio and Possible Longer Duty Cycle

Possible Better Loss-of-Coolant Accident Response

Possible Lower Fabrication Costs With Transuranics

\subsubsection{Possible Modified-Open Cycle By:}

Re-cladding Metal Rods for Use as LMR Targets

Or Providing a Metal Fuel/Target Stream for LMR Blend Stock

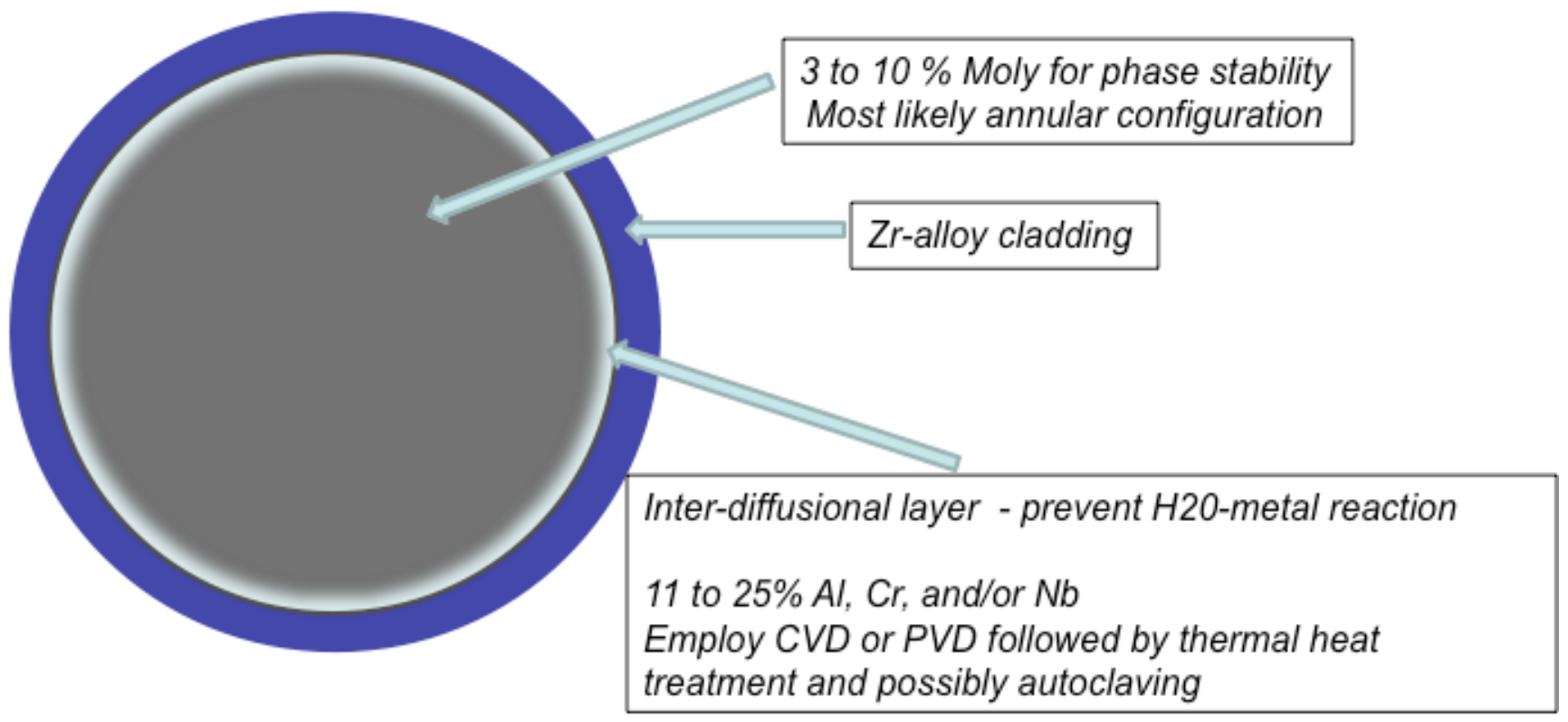

Figure 2. Schematic representation of metal alloy LWR fuel concept.

\subsubsection{Transformational Nature}

Introduces an Entirely New Way of Looking at the LWR and Its Fuel Cycle

Could Provide for Higher Core Powers or Larger Safety Margins

Could Reduce Long-Standing LOCA Concerns

Potentially Opens the Pathway to a Modified-Open Fuel Cycle 


\section{Additional Innovative Proposals}

The next seven highest ranked proposals were funded to do further feasibility studies through FY-2010. These proposals are listed below along with summary of the individual concepts.

Table 3. Innovative Proposals for FY-10 Feasibility Studies

\begin{tabular}{|l|l|l|l|}
\hline 4 & Dispersion Fuel & INL & $\begin{array}{l}\text { High burnup FR fuel concept. Incorporates TRU } \\
\text { microspheres in a matrix, supports closed fuel cycles as } \\
\text { well as some applications in modified open cycles. }\end{array}$ \\
\hline 5 & $\begin{array}{l}\text { Ultra-high Burnup Metallic Inert } \\
\text { Matrix Nuclear Fuel Concept }\end{array}$ & LLNL & $\begin{array}{l}\text { Provides an alternative, possibly revolutionary geometric } \\
\text { configuration and performance benefits, to traditional } \\
\text { metallic alloy fuels. }\end{array}$ \\
\hline 6 & $\begin{array}{l}\text { An Advanced High Integrity } \\
\text { Gas Cooled Fast Reactor Fuel }\end{array}$ & SRNL & $\begin{array}{l}\text { The development of ceramics without GFR emphasis. } \\
\text { We are interested in the MAX phase material } \\
\text { development proposed. MAX phase ceramics may have } \\
\text { the potential to improve ceramic fuel performance. }\end{array}$ \\
\hline 9 & $\begin{array}{l}\text { Multi-Layer Co-Extruded } \\
\text { Metallic Fuel for Fast Reactors }\end{array}$ & SRNL & $\begin{array}{l}\text { Multi-layer co-extrusion process may provide a } \\
\text { simplified fabrication process to traditional metallic alloy } \\
\text { fuel fabrication This activity is synergistic with the } \\
\text { Dispersion Fuel Concept and the proposers will be } \\
\text { working together. }\end{array}$ \\
\hline 10 & $\begin{array}{l}\text { Enhanced Thermal Conductivity } \\
\text { and Grain Boundary } \\
\text { Engineering for Oxide Fuels }\end{array}$ & ORNL & $\begin{array}{l}\text { May provide efficiency improvement that can be } \\
\text { implemented in existing and next generation LWRs. }\end{array}$ \\
\hline 11 & $\begin{array}{l}\text { High burn-up ceramic composite } \\
\text { Nuclear Fuels }\end{array}$ & LANL & $\begin{array}{l}\text { Very strong potential for MOC concepts. Potential for } \\
\text { mechanical separation of fission products without a need } \\
\text { for chemical separation. }\end{array}$ \\
\hline 12 & $\begin{array}{l}\text { Thorium Fuel Development Path } \\
\text { Forward }\end{array}$ & BNL & $\begin{array}{l}\text { Prepare a white paper on the thorium option } \\
\text { development. Multiple proposals were made. BNL } \\
\text { provides Thorium analysis capability and is principal or } \\
\text { collaborator on many. }\end{array}$ \\
\hline
\end{tabular}




\section{Rank 4: Innovative Transmutation Fuel Concept - Dispersion Fuel}

\subsubsection{Fuel Concept Description}

Dispersion fuel represents a relatively mature fuel technology already used in high power reactors and known for its ability to allow very high (>400,000 MWD/ton) fuel burnup without fuel failure issues. The high burnup potential comes from the encapsulation of fuel particles within a stable matrix that resists swelling and radiation damage and is largely unaffected by fission fragments. An innovative dispersion fuel concept for a deep burn transmutation fuel is outlined here. This dispersion fuel concept would utilize TRU fuel microspheres in a matrix of $\mathrm{Zr}$ or other appropriate metal to retain all fission products, limit swelling, and allow for high fuel burnup.

Dispersion fuels are normally not considered for transmutation because of the complexity in manufacturing, the volume of fission gas that is

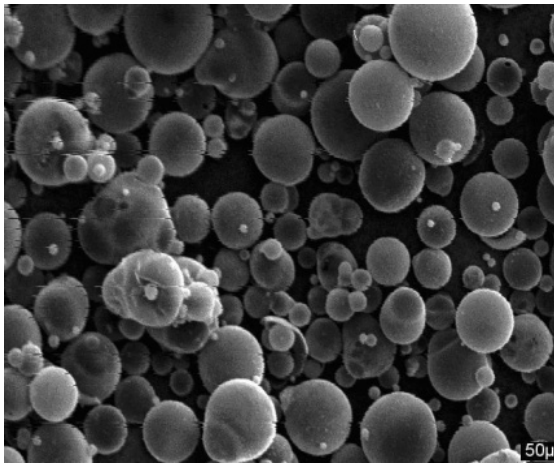

Figure 3. Carbon Microballons. generated, and the necessarily lower fissile density. This fuel concept simplifies fabrication while providing an integral fission gas plenum within the fuel particles to eliminate overall fuel swelling. It will allow for higher fissile densities by reducing the amount of inert matrix required. The process utilizes metal fuel coming from electrochemical separations. When the TRU is melted to separate and remove residual salt, the metal is atomized into solid microspheres. The dispersion fuel process physically overcoats the microspheres with a mixture of novolac phenolic resin and Bam ${ }^{\circledR}$ (or EnergyCost Power ${ }^{\circledR}$ ) hollow carbon microspheres (microballoons, Fig. 1) to provide a slight excess of carbon for formation of $\mathrm{TRUC}_{\mathrm{x}}$. Once cured and carbonized, the overcoated particles may then be used in two separate process approaches. For the highest fissile density dispersion fuels, the overcoated particles are heated sufficiently to form $\mathrm{TRUC}_{\mathrm{x}}$ particles with significant microporosity from the balloon structure, then mixed directly with a metal powder matrix, compacted and extruded. For a lower density but more protected dispersion particle, the initial overcoated particles are further overcoated with a metal powder, potentially $\mathrm{Zr}$, $\mathrm{Ti}$, or $\mathrm{Si}$ and a novolac resin at a ratio to provide sufficient carbon to form a matrix metal carbide. Furnace heating of the particles after the second overcoating cures and carbonizes the resin in the metal matrix. Additional heating reacts the overcoat metal and the TRU with the carbon to form $\mathrm{TRUC}_{\mathrm{x}}$ in a hard metal carbide shell to further protect and isolate the fuel carbide core.

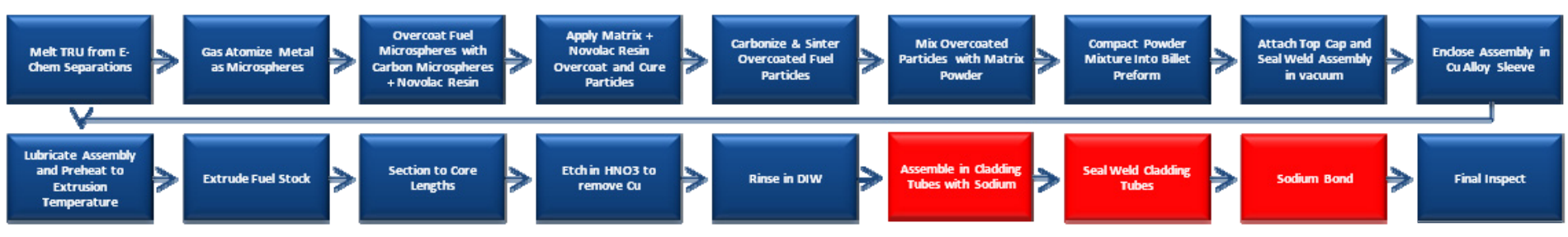

Figure 4. Dispersion Fuel Block Flow Diagram. Red boxed processes can be deleted if the extrusion canister is used as integral cladding.

With either particle design route, the finished particles (See Fig. 2 \& 3) may be combined with the metal matrix powder in a suitable canister, compacted, and extruded to fuel core dimensions, sheared to core lengths, and finished like standard metal fuel pins with a sodium bond. As an alternate higher fuel density method, the extrusion canister may be designed to form the fuel cladding and would be bonded to the matrix during coextrusion. This integral clad metallurgical bonding approach provides more space in 
the core for fuel by removing the sodium bond gap. It deletes some traditional fabrication steps (See Fig. 2) but would require installation of end caps to the fuel pins as is the case with traditional fabrication processes. The fabrication of the overcoated TRU particles requires an automated Freund-Vector Granurex ${ }^{\circledR}$ (or Glatt CPS ${ }^{\circledR}$ ) powder overcoater and appropriate furnace equipment with controls external to the hot cell. Powder overcoating has been demonstrated to provide well over $99 \%$ usable product and excellent product sphericity. Remotely operated designs for this equipment are already available from the pharmaceutical industry. Remote particle quality control is achieved using in-line laser particle size analysis.

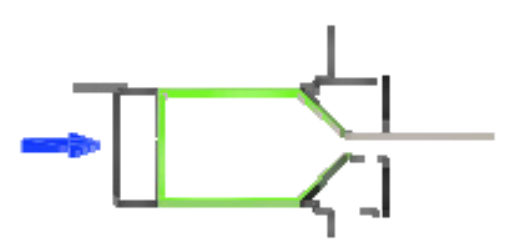

Figure 5. Schematic of extrusion process.
Billet preparation involves matrix powder and fuel particle blending and preliminary compaction into a suitable metal canister that is subsequently evacuated and seal welded. For the metal carbide coated fuel particles, the structural properties of the microballoons and the hard carbide outer shell of the particles should prevent the collapse of the processing. For the straight $\mathrm{TRUC}_{\mathrm{x}}$ particles, the structural integrity of the $\mathrm{TRUC}_{\mathrm{x}}$ is required to retain the plenum space in the particles. The carbon microballoons are available in different wall thicknesses. Bam ${ }^{\circledR}$ provides one with a density of $0.146 \mathrm{~g} / \mathrm{cm}^{3}$ and another with density $0.265 \mathrm{~g} / \mathrm{cm}^{3}$. The microballoons substantially reduce the overall physical fuel particle density to minimize any fuel particle settling or segregation between blending and compaction. A single billet of $5.3 \mathrm{~cm}$ diameter x $21.6 \mathrm{~cm}$ long extruded at around 195,000 $\mathrm{kg}$ (215 tons) force should make 25 fuel rods $(91.4 \mathrm{~cm} \mathrm{lg}$. x $0.51 \mathrm{~cm} \mathrm{dia.).}$

The integral cladding process route would use slightly different extrusion parameters and the ends of the fuel rods would be hot swaged to accept appropriate closure welded end caps (See Fig. 4).

\subsubsection{Fuel Reprocessing}

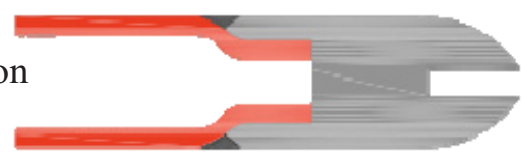

Reprocessing of this fuel will require a different head end, but incorporate standard fuel separations methods. The process flow, (See Fig. 5) involves chopping, then hydriding the used fuel matrix to reduce it to a fine powder that is then double leached to remove the TRU and fission product inventory. The metal matrix material can then be recovered for re-use in new recycled fuel if desired, but this recovery and re-use is optional.

\subsubsection{Potential Benefits of the Fuel Concept}

This fuel concept is rooted in historical dispersion fuel technologies but is highly innovative due to application of new materials and fabrication methods that are expected to give it performance characteristics far beyond anything done previously:

1. The finished fuel contains only TRU, carbon, metal matrix and the sodium bonded outer cladding (if needed).

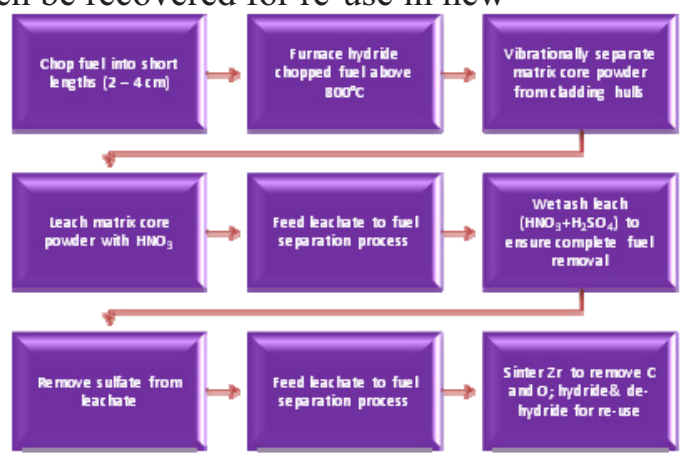

Figure 7. Proposed separations process for dispersion fuel concept. This is a relatively simple fuel composition which helps simplify manufacture and separations.

2. The use of the new structurally sound hollow carbon microspheres with $6-12 \%$ of the density of graphite, allows formation of a bonded honeycomb structure. When reacted with TRU metal, a TRUcarbide closed cell foam structure with excellent heat transfer and fission product trapping space is 
expected to result. The structurally sound metal matrix will further contain any swelling and fission product damage.

3. Lanthanide fission products will be encapsulated and physically separate from the sodium bond and the external fuel cladding to prevent destructive fuel-cladding interaction.

4. Since the gas plenum is in the fuel particle, additional plenum at the end of the fuel pin is eliminated and the element lifetime is extended beyond that of traditional dispersion fuels without an integral plenum.

5. Because of the encapsulation of fission products within the fuel or inert metal matrix, as opposed to the cladding, burnup should be limited only by the fissile content as opposed to fuel cladding interactions. Longer burnup equates to lower fuel usage, more infrequent reactor core refueling shutdowns and higher reactor operating efficiencies.

6. Elimination of the upper plenum space above the fuel allows reduction of the height of the reactor vessel by twice the plenum length providing a significant reduction in capital cost while providing a more compact reactor vessel without reducing power output.

7. The fuel can be readily re-processed using known technologies and the matrix can be recovered and re-used.

\subsubsection{Fuel Research and Development Team}

The R\&D Team will involve the following:

- INL personnel will conduct initial concept development, conceptual fuel process design, and development of fabrication process flow diagrams.

- SRNL will assist with fuel extrusion parameters and perform initial extrusion demonstrations.

- INL personnel will perform required neutronics analysis and power performance analysis

- INL separations personnel will develop the detailed fuel recycling process flow diagram

The INL R\&D team will provide an initial assessment of the R\&D that will be required to develop and qualify this potential fuel form. 
1. U.5. DERANTMENT of

\section{Dispersion Fuel for Transmutation}

Nuclear Energy

TRU carbide particles dispersed in a metal matrix pin-type fuel

- Plenum space is provided within the fuel particles

- Uses new technologies

- Carbon microballoon plenum

- Fluid bed powder overcoating

- TRU overcoated with powder \& resin then thermally treated to form carbide

Advantages:

- No plenum above fuel in reactor core design

- Uitra high burnup potential

Microballoon powder ensures

plenum space

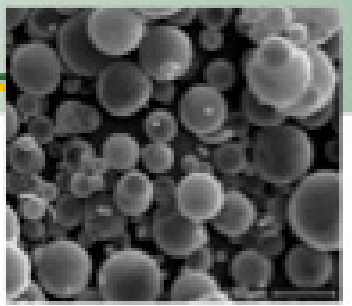

- Cladding protection from lanthanides

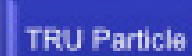

Overcoating

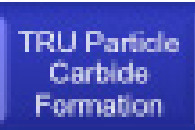

Matal Matrix 8

Particle

Moing

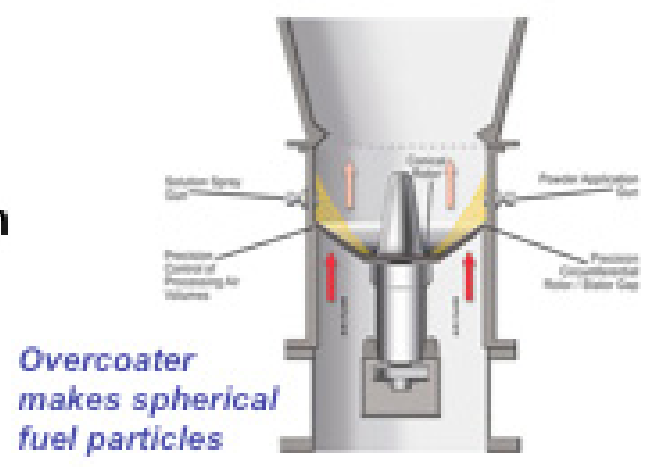

fuel particles

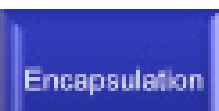

Extrusion 8

Sectioning

Fuel Pin

Finishing

Figure 8. Overview graphic of dispersion fuel proposal. 


\subsection{Rank 5: ULTRA-HIGH BURN-UP METALLIC INERT MATRIX NUCLEAR FUEL CONCEPT}

Most nuclear reactor concepts are presently based on Gen-II+ technology. Currently, there is a push toward higher burn-up, e.g. from $2-5 \%$ to $10+\%$, that requires an acceleration of the fuel development and qualification cycle. In order to move toward Gen-IV and beyond, high-performance fuels and the associated cladding materials are critical-path milestones that will require a science-based R\&D experimental and modeling approach beyond what is currently available.

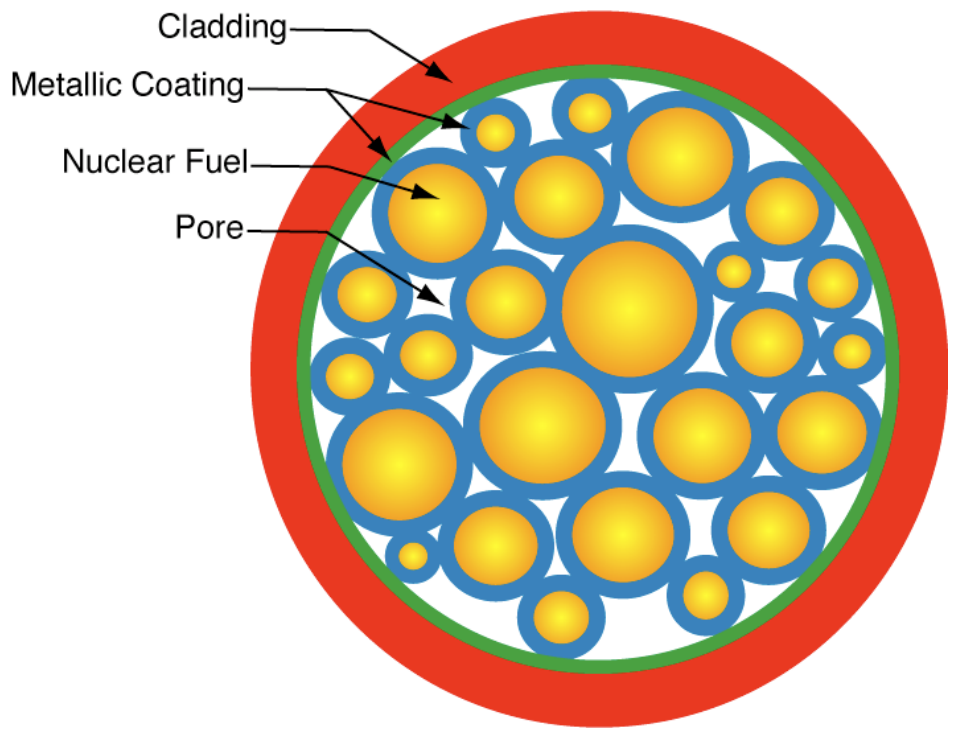

Figure 9. Schematic of ultra-high burnup IMF fuel design concept.

This project proposes the development of an advanced UHBU (Ultra-High Burn-Up) IMF (Inert Matrix Fuel) design that will meet the requirements for next generation advanced nuclear energy systems. This fuel form will be achieved by new methodologies that will enable accelerated design based on a fully validated and integrated science-based platform resulting in a shorter timeline for fuel development, performance optimization, and qualification. Variations of the concept may prove viable for thermal reactors, fast reactors, and for minor actinide (MA) transmutation targets.

\subsubsection{Fuel Concept}

We propose to build upon a dispersion type pelletized IMF fuel concept that was recently suggested by the Bochvar Institute. This new fuel is reported to improve fuel performance for thermal reactors (PWR and BWR) and can replace container-type fuel rods for the sodium-cooled fast-reactor option of Gen-IV. The fuel consists of compacted actinide fuel particles (metallic or oxide) coated by a metallic alloy within a cladding material. A schematic of the important features of this fuel form are shown in Figure 9. These features include a pelletized metal fuel, a metal alloy coating of the fuel pellets as well as the cladding, and intrinsic headspace by virtue of the pores arising from the packing of the pellets.

\subsubsection{Innovative Approach to Fuel Performance}

This IMF optimizes fuel density (i.e., power conversion) and thermal transport (i.e., heat dissipation) while overcoming many of the past deficiencies associated with conventional metallic fuel rods and oxide-pellet fuels. The metallic matrix occupies very little volume compared with the fuel meat, whereas the porous structure can accommodate fission gases (FG) with minimum swelling. The Zr-based matrix is expected to be radiation resistant to damage by fission products (FP). In comparison with MOX, this metallic IMF exhibits an efficient metallurgical bond between fuel and cladding, protection against fuelcladding interaction, while uniformly distributing fuel particles in the metallic matrix. Fabrication 
involves an environmentally friendly dust-free and low-cost process using coated alloy fuel kernels. By a proper packing of the coated fuel meat, this fuel form can accommodate transuranics for near-complete transmutation, either as driver fuel or irradiation targets. Finally, the reprocessing flow sheet for this fuel form will include either an electrochemical process or a non-chemical physical re-fabrication such as castmelt or partial oxidation-reduction. As an MA fuel or target, process temperature may be constrained to limit actinide volatility.

This metallic IMF fuel design is applicable to both uranium fuels and importantly, to Pu plus MA. By adjusting the size of fuel pellets, a high-fuel content and a high pore volume fraction can be achieved. The wide potential range of fissile to matrix opens possible application to high burn-up thermal-reactor fuel at one extreme, and to fast-reactor fuel and targets at the other. It is also worth noting that the added solute elements in the $\mathrm{Zr}$ alloy not only decrease the melting temperature of pure $\mathrm{Zr}$ significantly, but also separates fuel from cladding to permit optimization of fuel meat, (U, Pu, and MA) and FP (e.g., iodine, cesium, and cadmium), versus cladding compatibility. This IMF exhibits many properties needed for UHBU fuel, including excellent thermal conductivity and adaptability to a wide range of actinide mixtures. The pelletized structure of the fuel builds headspace directly into the fuel geometry, mitigating the swelling that can occur in metallic fuels at UHBU. An important feature is the high effective thermal conductivity achieved by the intimate contact of the metal matrix to the metal coating of the cladding. From phase diagram studies and appropriate modeling tools, the composition of the metal matrix properties can be optimized through metallurgical tuning of its alloy constituents.

\subsubsection{Transformational approach to UHBU IMF}

The development of this UHBU IMF fuel will begin with a thorough technical assessment of the Russian fuel design. This will allow us to identify and then to focus on the technology gaps. This analysis will be folded into a comprehensive detailed path forward of our own, emphasizing the application of this fuel to UHBU in fast reactors and to performance improvement in oxide-fueled LWR systems. For example, of particular concern are the details of the evolution of the fuel with burn-up and of the fuel-cladding bond, notably with the most advanced variants of the fuel form containing Pu and MA. The Russian fuel design appears to offer the possibility for dramatically advancing the utilization of metal fuels.

Modern out-of-core experimental methods and state-of-the-art theory, simulation and modeling will address the identified technology gaps. The R\&D team brings relevant capabilities to this fuel concept in the areas of metallic fuels, ion-beam accelerated aging, and advanced simulation and modeling of materials far from equilibrium. Computational methods ranging from atomistic scale, through mesoscale, to the continuum will be employed. An important element in the development of advanced nuclear fuels is to consider, from the outset the various aspects of proliferation risk and prevention. The research team assembled for this design study is well qualified to assess and quantify these risks for the complete fuel cycle as a part of the detailed conceptual fuel design.

This project will establish a research path that describes a transformational rapid protocol for the development and qualification of this proposed UHBU IMF. The components of this plan will include: modern computational materials science tools; targeted fabrication and characterization; probing of mechanisms that influence the performance of the UHBU fuel using ion beam experiments along with selected in-pile reactor-testing experiments. The proposed IMF concept will also provide a new sciencebased platform that will transform fuel development methods and qualification processes.

This IMF fuel lends itself to the separate study of each of its functional components: the fuel meat; the metal matrix; and the fuel-cladding interface. This "separability" will serve as our basis for detailed modeling and experimental validation that will lead us to a more rapid methodology for the development and the qualification of this fuel form. 


\subsubsection{R\&D Plan and Team}

A detailed conceptual fuel design for a dispersed porous metallic IMF UHBU-fuel will be laid out and include: a flow diagram of process fabrication; neutronic analysis; temperature and power performance; a proliferation risk assessment; and a recycle flow diagram. Special emphasis will be given to R\&D component development highlighting and closing technology gaps and advancing the fundamental scientific basis for the evolution of UHBU metallic IMF advanced nuclear energy fuel systems. The proposal will bring together a team of experts that has a long history of successful involvement in fuel design and

\section{(d) ENERGY Ultra-High Burn-Up Metallic Inert Matrix Fuel (IMF) \\ Nuclear Energy}

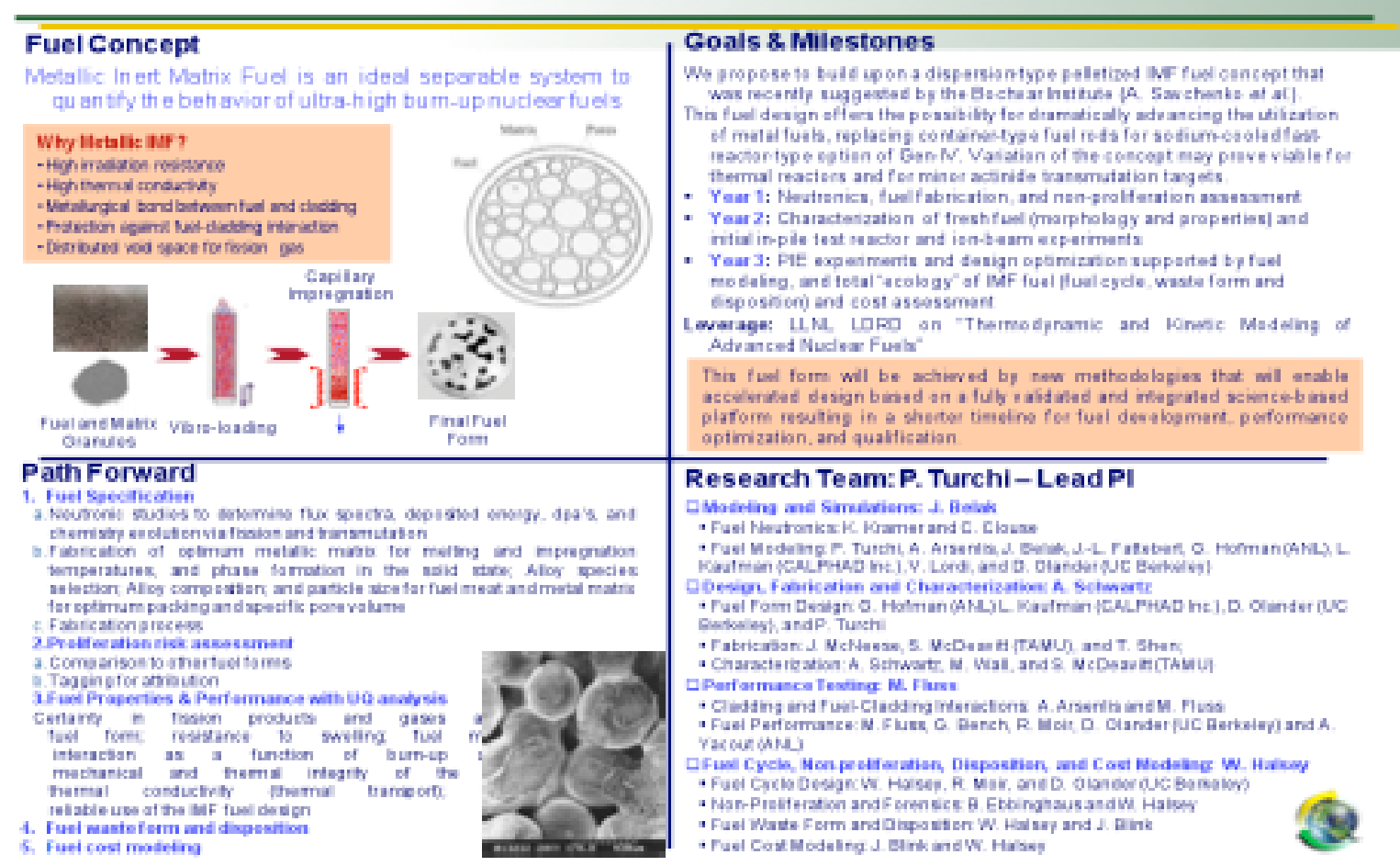

Figure 10. Graphic summary of ultra-high burnup IMF concept. 


\subsection{Rank 6: An Advanced High Integrity Gas Cooled Fast Reactor Fuel}

Thad Adams ${ }^{1}$, James Tulenko ${ }^{2}$, Travis Knight ${ }^{3}$, Elizabeth Hoffman ${ }^{1}$, and Michel Barsoum ${ }^{4}$

${ }^{1}$ Savannah River National Laboratory, ${ }^{2}$ University of Florida, ${ }^{3}$ University of South Carolina, and ${ }^{4}$ Drexel University

\subsubsection{Proposed Concept}

The proposed effort seeks the development of a very high integrity fuel for Gas-cooled Fast Reactor (GFR) applications. This innovative fuel design consists of a pin-type GFR fuel comprised of a mixed phase carbide fuel (U, Pu, Minor Actinides (MA))-C clad with a layered ternary carbide/nitride or socalled MAX phase material. The proposed fuel concept makes use of the most optimal fuel material for a gas-cooled fast reactor in conjunction with a truly revolutionary clad material to produce an advanced fuel form with the potential to reach the $400 \mathrm{GWd} / \mathrm{MT}$ high burnup capability. Previous neutronics analyses have demonstrated the preference of carbide fuel materials over both oxide and nitride-based fuelsespecially burnup (heavy metal) and manufacturing cost (no N-enrichment). The critical factor limiting full adoption of carbide based fuels for GFR applications to high burnup has centered on cladding compatibility and long-term integrity. Various cladding materials have been evaluated for potential use in carbide-based GFR applications; these materials include base materials such as B, C, Nb, Mo, Ta, W, and $\mathrm{SiC} / \mathrm{SiC}$ composites. Of these materials the $\mathrm{Nb}$-based alloys have received the most attention and currently various organizations are also exploring the advanced $\mathrm{SiC}$ materials. However, neither of these material systems has been demonstrated to be wholly acceptable and optimal for GFR cladding. A new high-temperature material, the MAX phases, is proposed for claddings. The $M_{n+1} A X_{n}(M A X)$ phases are layered machinable ternary carbides and nitrides, where $\mathrm{M}$ is an early transition metal, $\mathrm{A}$ is an A-group element and $\mathrm{X}$ is $\mathrm{C}$ and/or $\mathrm{N}$. These novel compounds offer a unique combination of properties, some of which are typical of ceramics; others more typical of metals. These conductive MAX phase materials possess excellent high-temperature strength and ductility $\left(25 \%\right.$ plastic tensile elongation at $\left.1000^{\circ} \mathrm{C}\right)$, fracture toughness $\left(8-16 \mathrm{MPa}-\mathrm{m}^{1 / 2}\right.$ at $\left.25^{\circ} \mathrm{C}\right)$, and both creep and fatigue resistance. The MAX phase materials proposed for this program have a modulus of elasticity of $333 \mathrm{GPa}$, coefficient of thermal expansion is $9.1 \times 10^{-6}{ }^{\circ} \mathrm{C}^{-1}$, and a thermal conductivity of $34 \mathrm{~W} / \mathrm{m} \mathrm{K}$ at $950{ }^{\circ} \mathrm{C}$. Recently, irradiation programs have been initiated by project team members to characterize the response of the MAX phase materials to high temperature $\left(1000^{\circ} \mathrm{C}\right)$, high dose $(9 \mathrm{dpa})$ fast neutron irradiation.

Objectives addressed in this effort include:

- Optimization of concept - fuel material composition, identification of fuel fabrication methodology, MAX phase cladding materials selection, and MAX phase clad application technology

- Development of mixed carbide phase fabrication methods consistent with MA compositions

- Precursor materials/techniques for (U, Pu, MA) carbide materials

- Determine conditions for fabrication of controlled porosity pellets to accommodate carbide fuel swelling.

- Reduced temperatures and/or shorter processing times to accommodate the intended MA composition

- Analysis of MAX phase cladding manufacturing process

- Fabrication and machining strategies

- Reactor neutronics for (U, Pu, MA)-C fuel with MAX phase cladding

- Economic analysis for fuel fabrication

- Evaluation of fuel recycle 
- Use of existing oxide-LWR fuel for precursor materials

- Chemistry for (U, Pu, MA)-C fuel with MAX phase material clad reprocessing

- Identification of R\&D needs for the fuel concept outlined in a technology development roadmap

\subsubsection{Concept Benefits}

In general, the proposed (U, Pu, MA)-C GFR fuel with MAX phase cladding offers the potential to meet GenIV requirements to make nuclear power a truly sustainable energy source by providing:

- High temperature $\left(>850{ }^{\circ} \mathrm{C}\right)$ for process heat and high thermal efficiency

- Ability to operate on a variety of feedstocks including used LWR fuels

- Fast neutron spectrum for design flexibility to operate as a transuranic (TRU) burner OR as a breeder, depending on fuel and core design

- TRU burner to reduce Pu stockpiles and reduce HLW

- High conversion or breeding ratios for efficient resource utilization

- High burnups for improved fuel cycle economics

- Higher power densities for smaller reactor vessels and containments (cost savings)

Making use of a MAX phase material as a cladding, the proposed fuel design offers the potential to:

- Enable high efficiency chemical process heat usage

- Maintains mechanical properties at temperatures of $1000^{\circ} \mathrm{C}$ or more

- Increase fuel cladding integrity at higher burnup - on the order of $400 \mathrm{GWd} / \mathrm{MT}$

- High fracture toughness and ductility compared to traditional ceramics

- Increase design flexibility

- Fabricated by traditional ceramic processes, plus machinable and spray coating techniques

\subsubsection{Project Team}

Dr. Thad Adams, Savannah River National Laboratory--Dr. Thad Adams received his M. S. (1994) and Ph. D. (1997) from the University of Florida in Materials Science and Engineering; prior to this his B.S. degree was earned from the University of Tennessee. His studies have concentrated on the liquid metal corrosion/embrittlement, advance nuclear fuel development, phase transformations and microstructural evolution in advanced materials.

Dr. Elizabeth Hoffman, Savannah River National Laboratory--Dr. Hoffman received her Ph. D. (2006) from Drexel University in Materials Science and Engineering. Dr. Hoffman's published research includes synthesis and characterization of nanoporous materials. She is presently investigating the response of MAX phase materials to neutron irradiation in the Advanced Test Reactor and the Massachusetts Institute of Technology Reactor in collaboration with Professor Michel Barsoum of Drexel University.

Professor James Tulenko, University of Florida--Professor Tulenko received his BA in Applied Physics, from the Harvard University, in 1958, an MA in Applied Physics from Harvard University in 1960, an MS in Nuclear Engineering from MIT in 1963 and MBA from George Washington University in 1980. Professor Tulenko has been at the University of Florida since 1986 where up until 2001 he was the Chair of the Nuclear and Radiological Engineering Department. Prior to that, he spent 15 years at Babcock \& Wilcox. Professor Tulenko has had over 10 million dollars in research as the Principal investigator at the University of Florida for DOE Contracts 
Dr Travis Knight, University of South Carolina-- Dr. Knight has more than ten years experience working with advanced nuclear fuels for a wide range of applications including high temperature space nuclear fuels and coated particle fuels. Many of the techniques used and developed by Dr. Knight in his previous experience are directly applicable to the work outlined in this proposal.

Professor Michel Barsoum, Drexel University--Professor Barsoum and his research group were the first to fabricate and fully characterize an important new class of machinable ternary carbides and nitrides MAX Phases. Since 1996, when the first paper on the subject was published, Professor Barsoum and his collaborators have published over 100 refereed papers on these ternary carbides and nitrides alone including ones in Nature and Science and Physical Review Letters.

Budget: Total estimated task budget $\$ 575 \mathrm{~K}$

\section{(D) ËNERGY Advanced Fuel Materials - MAX Phase Ceramics \\ Nuclear Energy}

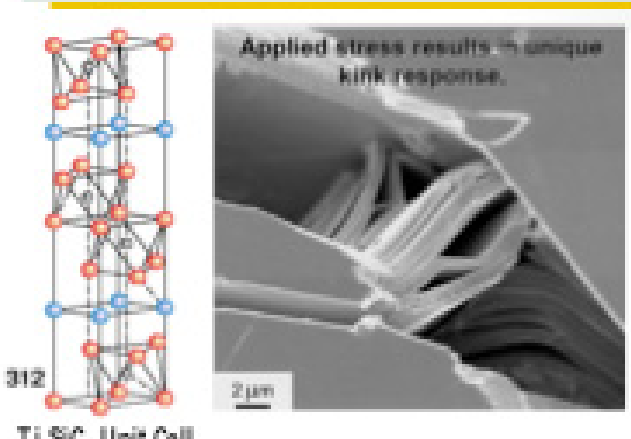

$\mathrm{Ti}$,SC, Unit Call
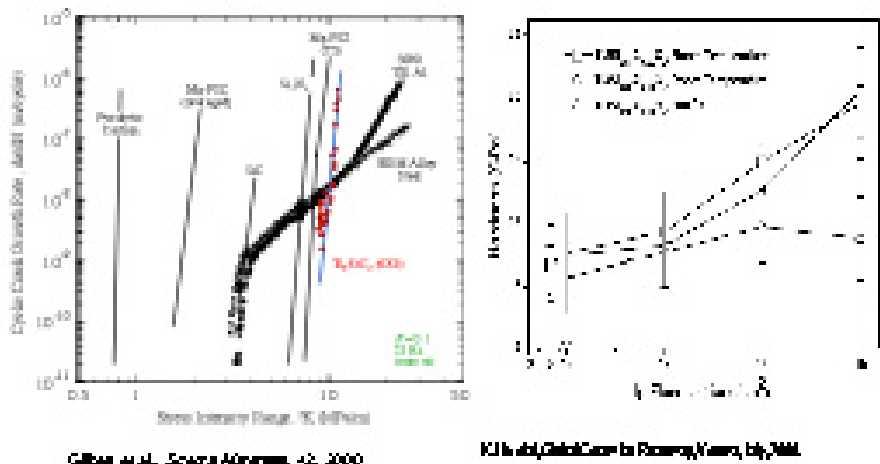

-MAX Phase Ceramies= family of temary carbides $(M=$ early transition, $\mathrm{A}=$ group $\mathrm{A}$ element, $\mathrm{X}=\mathrm{C}$ or $\mathrm{N}$ ) have thermalmechanical properties that are attractive to nuclear applicafions -SRNL evaluating $T_{3} S I_{C_{3}}$ and $T_{3} \mathrm{AIC}_{3}$

- Have high temperature mechanical stabiity (including ereep resistance, and R-curve behavior) as a monolith

- Creep resistant in compression and tension. -Stress-strain responsesignificanty vates with rate. -Up to $4 \%$ strain without fomation of voids. ofalue strain $8 \%$

-MAX Phase Ceramies have high thermal conductivity -Irradiations set up for MITR and ATR $\left[1000^{\circ} \mathrm{C}\right.$ up to 7 dpa) to investigate response and compare to the $\mathrm{SiC}$ that is of course leading candidate for high $T$ nuclear

-SRNL Innovative Fuels Project-Prepare Technology Development Plan for MAX Phase Ceramics for Advanced Nuclear Applications

Figure 11. Graphical summary of MAX Phase Ceramic Concept. 


\subsection{Rank 7: Multi-Layer Co-Extruded Metallic Fuel for Fast Reactors}

Thad Adams ${ }^{1}$, James Tulenko ${ }^{2}$, and Travis Knight ${ }^{3}$,

${ }^{1}$ Savannah River National Laboratory, ${ }^{2}$ University of Florida, ${ }^{3}$ University of South Carolina

\subsubsection{Proposed Concept}

Metallic fuel system are being developed for fast reactors - sodium cooled fast reactors - in order to promote burn of long lived fission products form used nuclear fuel. Typical metallic system currently under consideration are $\mathrm{U}-\mathrm{Pu}-\mathrm{MA}-\mathrm{Zr}$ alloys with varying concentration of $\mathrm{U}, \mathrm{Pu}$ and minor actinides (MA) - Am, Cm, Np. Current fabrication techniques under development for these metallic fast reactor fuels center on liquid phase casting technologies. Some advantages of metallic fuel systems are their high thermal conductivity, potential for high fissile and fertile densities, and the small Doppler reactivity. However, two major challenges for metallic fuels are their lower melting temperatures and their increased propensity for fuel-clad interactions. An additional concern for these fuels during the fabrication process is the volatility of MA's during cast processing and overall materials losses in casting skull/scrap.

The objective of the proposed work is to develop a metallic fast reactor fuel system based off of a combined powder processing and forming operation to produce a fuel system with increased integrity, capable of higher burnup, reduced TRU volatility, and reduced materials losses. The Multi-Layer CoExtruded metallic fuel system (MCOE) will be based on the U-Pu-MA-Zr system processed via a powder metallurgy route in conjunction with a consolidation process - multi-layer co-extrusion-- to produce a multi-layered fuel comprised of U-Pu-MA-Zr fuel core, reaction resistant interlayer-either metallic $(\mathrm{Cr}, \mathrm{V})$ or more ductile ceramic ( MAX Phase-- $\mathrm{Ti}_{3} \mathrm{SiC}_{2}$ and $\mathrm{Ti}_{2} \mathrm{AlC}$ ) — and steel clad ( eg, HT-9).

Fabrication of this multi-layer metallic fuel system will be based on a multi-layer co-extrusion process whereby green powder fuel compacts will be assembled into an inner reaction layer can which is then in turn loaded into an outer layer HT-9 can-Figure 12. This multi-layer assemblage will then be simultaneously co-extruded to produce a controlled density fuel core with inner reaction layer and outer cladding. This MCOE fuel will result in improved fuel burnup and overall fuel integrity for metallic based fast reactor fuel systems.

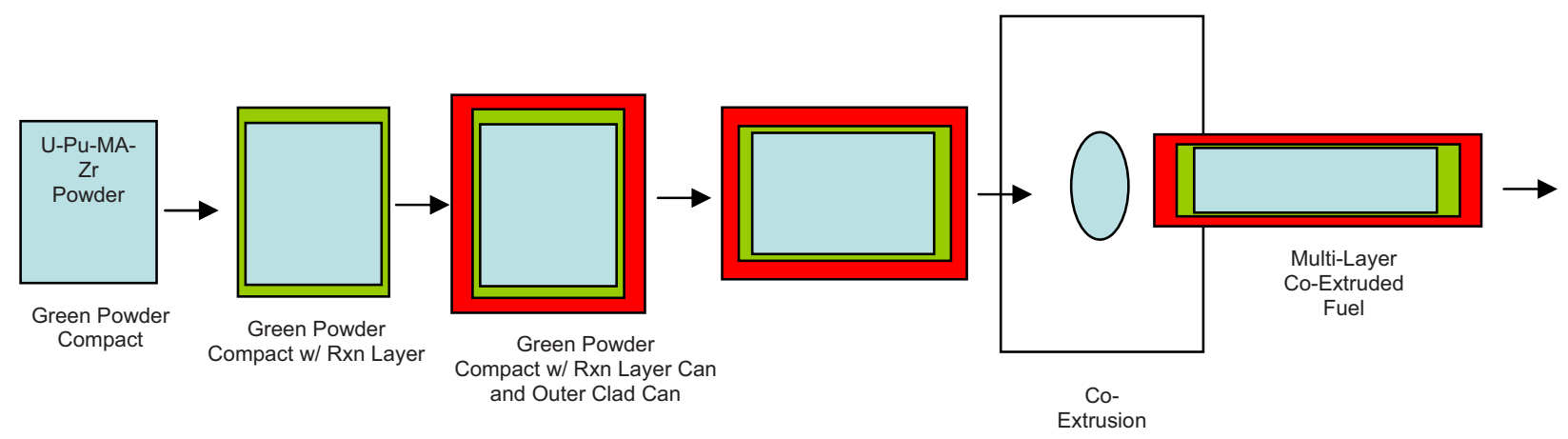

Figure 12. Multi-Layer Co-extrusion Fuel Fabrication

\subsubsection{Concept Benefits:}

The development of a lower temperature powder metallurgy type materials processing technique for fabrication of this metallic-based fast reactor fuel address one of the major program concerns with respect to metallic fast reactor fuel development. Minor actinide volatility and in-general, material losses associated with metal casting based processes for fabrication of these metallic fuels is currently a major concern in the development of metallic fuels. Metal casting processes with process temperature in the range of $1200-1400^{\circ} \mathrm{C}$ can result in significant amounts of MA losses - in some case on the order of $75 \%$. Modified casting techniques utilizing gas atmosphere overpressures have reduced the MA losses but have not completely eliminated them. The proposed seeks to eliminate the MA-loss issue via one of two 
routes-1) perform the co-extrusion operation and moderate temperatures $500-700^{\circ} \mathrm{C}$ and 2 ) with the powder metallurgy approach allow for the MA to be incorporated into the green body in higher stability forms such as oxides (i.e., $\mathrm{AmO}_{2}$ ). It is anticipated that either of these approaches can be utilized to eliminate MA volatility. In addition to the elimination of minor actinide losses using the powder metallurgy approach, as one considers commercial fuel fabrication vendors, the use of a powder blending and consolidation approach is more in-line with their existing techniques and approaches. While the inclusion of the MA's in these fuels forms will impose the need for remote fuel fabrication much of the base powder handling and consolidation technology required for the multi-layer co-extruded fuel design is wholly consistent with current powder-based fuel fabrication technologies. Lastly, given the metallic nature of the proposed MCOE fuel, recycle via conventional aqueous reprocessing flowsheets or with pyrochemical technologies would be possible. A potential challenge with the MCOE fuel design concept is the matching of the extrudibility between the reaction interlayer $(\mathrm{Cr}, \mathrm{V}$ or ductile ceramic like MAX phase-- $\mathrm{Ti}_{3} \mathrm{SiC}_{2}$ and $\mathrm{Ti}_{2} \mathrm{AlC}$ ) and the outer clad alloy ( HT-9). A critical element to integrity of the MCOE fuel will be ensuring that no bare spots arise as a result of tearing /cracking of the reaction interlayer materials during the co-extrusion operation. It is anticipated that using a "warm" co-extrusion process should aid in eliminating this potential issue.

The proposed effort for the FCRD Innovative Fuel Design program will focus on further enunciation of the proposed fuel system composition and materials, flowsheet development for fuel fabrication, reactor performance simulations for the MCOE fuel system, and recycling flowsheet development.

\subsubsection{Project Team:}

Dr. Thad Adams-Savannah River National Laboratory--Dr. Thad Adams received his M. S. (1994) and Ph. D. (1997) from the University of Florida in Materials Science and Engineering; prior to this his B. S. degree was earned from the University of Tennessee. His studies have concentrated on the liquid metal corrosion/embrittlement, advance nuclear fuel development, phase transformations and microstructural evolution in advanced materials.

Professor James Tulenko-University of Florida--Professor Tulenko received his BA in Applied Physics, from the Harvard University, in 1958, an MA in Applied Physics from Harvard University in 1960, an MS in Nuclear Engineering from MIT in 1963 and MBA from George Washington University in 1980. Professor Tulenko has been at the University of Florida since 1986 where up until 2001 he was the Chair of the Nuclear and Radiological Engineering Department. Prior to that he spent 15years at Babcock \& Wilcox. Professor Tulenko has had over 10 million dollars in research as the Principal investigator for DOE Contracts.

Dr Travis Knight-University of South Carolina-- Dr. Knight has more than ten years experience working with advanced nuclear fuels for a wide range of applications including high temperature space nuclear fuels and coated particle fuels. Many of the techniques used and developed by Dr. Knight in his previous experience are directly applicable to the work outlined in this proposal.

Budget: Estimated total task funding $\$ 525 \mathrm{~K}$ 


\section{U.s. DERARTMENT of \\ ENERGY \\ Advanced Fuel Materials - Multi Nuclear Energy -Layer Co-Extrusion}

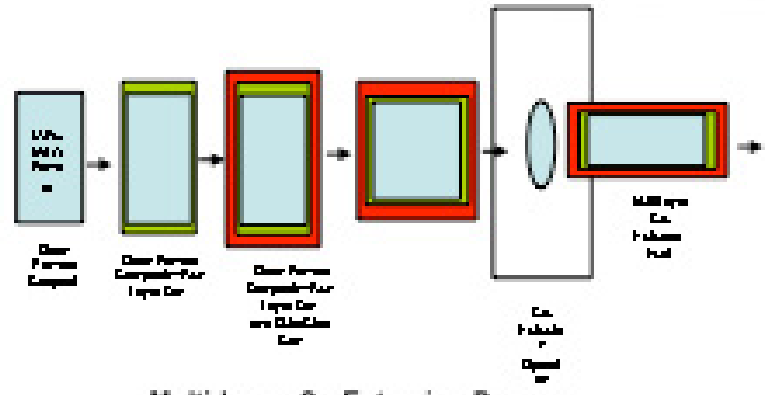

Multi-Layer Co-Extrusion Process

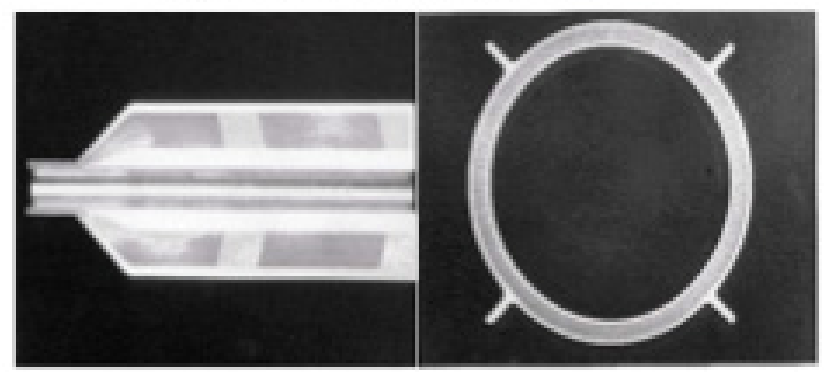

Co-Extruded Powder Metallurgy Al-U, $\mathrm{O}_{3}$ Fuel Tube
-Multi-Layer Co-Extrusion (MLCE) allows for the Production of Metallic Fast Reactor Fuels with an Integrated FCCI Protection Layer and Cladding in a Single Fabrication Process

-Benefits of MLCE

-ReducedEliminate $\mathrm{FCCl}$ - Metallurgical Bond

- Tailor Microstructure for Ln -Management

- Transient Liquid Phase Banding-Achieve Final Density \& Ln RXN

-Utilizes Known Clad Materials -FMS Materials Well-Characterized

-Attractive Fabrication Cost

-Challenges for MLCE

-Co-Extrusion of Multipla Materials/Layers with Varying Workability Properties

-Remote Co-Extrusion/Fabrication Processes

-SRNL Innovative Fuels Project-Prepare Technology Development Plan for Multi-Layer Co-Extrusion Fabrication of Metallic Fuels

Figure 13. Graphical summary of Multi-Layer Co-Extruded Metallic Fuel for Fast Reactors Concept. 


\subsection{Rank 8: Enhanced Thermal Conductivity and Grain Boundary Engineering for Oxide Fuels}

\subsubsection{Introduction/Motivation}

Commercial Light Water Reactors (LWR) use $\mathrm{UO}_{2}$ fuel because it is stable, non-reactive, and inexpensive to manufacture compared to other fuel forms. However, certain bulk properties of $\mathrm{UO}_{2}$ fuel impose significant limitations on reactor operations. The most limiting $\mathrm{UO}_{2}$ property is its low thermal conductivity, which decreases with increasing temperature and burn-up. The low thermal conductivity of $\mathrm{UO}_{2}$ results in a very high centerline-to-edge fuel temperature which contributes to fuel damage and fission gas release, limits the total reactor power density and burn-up, and increases the stored heat energy which needs to be dissipated during a transient event such as a loss of coolant accident (LOCA).

\subsubsection{Project Description}

The objective of the proposed research is to produce an advanced nuclear fuel based on $\mathrm{UO}_{2}$, suitable for existing and future nuclear reactors, which will use the existing fuel fabrication infrastructure with minimal modification. There are two separate but related elements to the proposed research: (1) increased thermal conductivity and structural strength through the addition of highly conducting fibers to $\mathrm{UO}_{2}$ powder prior to compression and sintering and (2) retarding grain growth and improving thermal conductivity through the addition of second phase particles at the grain boundary. Each line of research is separately described below.

\section{Element (1) Addition of highly conducting fibers}

For many years the addition of fibers to ceramics has been standard practice to increasing the bulk material toughness. The proposed research is designed to investigate the bulk thermophysical properties of the $\mathrm{UO}_{2} /$ fiber composite for different fibers and examine how the proposed new composites behave in a nuclear reactor. The tasks in this proposal examine different aspects of the compacts and include the following:

1. Examine different types of fibers in the compacts with the intent of increasing the bulk thermal conductivity. Several types of fibers will be investigated including but not limited to; fiber composed of planar graphite, graphite nanotubes, and pure tungsten wire approximately 10 microns in diameter.

2. Examine different types of coating for the fibers. There is concern that during the sintering process uncoated graphite will interact with the $\mathrm{UO}_{2}$, thus initial investigations include attempting to interact a thin $\mathrm{SiC}$ layer on the graphite fibers prior to mixing them with the $\mathrm{UO}_{2}$. Other types of protective layers will be investigated that contain materials having advantageous neutronic properties such as $\mathrm{B} 4 \mathrm{C}$.

3. A preliminary set of thermal calculations was performed on the change in bulk thermal conductivity of compacts as a function of fiber content. Initial calculations assumed the fibers had an axial thermal conductivity of $2000 \mathrm{~W} / \mathrm{mK}$ and a radial thermal conductivity of $10 \mathrm{~W} / \mathrm{mK}$. This effort will expand the range of computer simulations and include different heat transfer characteristics.

4. SiC fibers have also been added to oxide ceramics to tailor properties, such as increasing fracture strength and toughness and thermal conductivity. An approach will be undertaken to gain understanding of how to optimize the microstructural stability of polycrystalline $\mathrm{UO}_{2}$ incorporating different types of fibers. This includes examining the binding characteristics between materials and their expansion coefficients.

5. Preliminary investigations have shown that the addition of graphite fibers to $\mathrm{UO}_{2}$ fuel does not affect the neutronic characteristics of the fuel beyond the reduction in uranium that is displaced and reduction in fuel temperature. A more detailed set of reactor physics calculations will be done taking 
into account different composite characteristics and materials; i.e. power levels, enrichments, burnable poisons coatings on fibers, tungsten fibers, etc.

6. Using a detailed reactor physics code, determine the power level increase possible in a standard PWR and BWR assuming the bulk thermal conductivity of the fuel is increased by different amounts. The total power increase will be limited by the amount of water that can be pumped through the reactor and the pressure drop across the reactor fuel region as well as several fuel parameters such as the DNB point and fuel centerline temperature margin to melt.

7. Begin preliminary design on an instrumented irradiation rig to examine the characteristics of several composite types. The rig should be able to continuously measure fuel pellet centerline temperature of each pellet. The configuration would include unmodified $\mathrm{UO}_{2}$ pellets as a baseline control.

\section{Element (2) Grain boundary modifications}

Fission gases (Xe, $\mathrm{Kr}$ ) produced during fission has low solubility in $\mathrm{UO}_{2}$, and after a relatively short irradiation period a large number of fission gas filled bubbles are generated within the fuel grain. The gas atoms migrate to the grain boundaries unless trapped by bubbles. At temperatures where ample grain growth occurs, processes like grain boundary movement can sweep up fission gas atoms more rapidly than they could have arrived at the boundary by diffusion. The proposed work will evaluate the restraint of grain growth and the immobilization of solid fission product inclusions through pinning of grain boundaries by second phase precipitates.

1. First is the introduction of second phase particles at the grain boundaries of the polycrystalline $\mathrm{UO}_{2}$ to pin the $\mathrm{UO}_{2}$ grain boundaries and prevent excessive grain growth, which is an established mechanism for refining the grain size and stability in ceramics. In the present case, one must determine the stability of the second phase particles in terms of both their coarsening behavior and interaction with the matrix at the temperatures expected to be experienced by the fuel element.

2. Initial studies would employ $\mathrm{CeO}_{2}$ as the matrix (also fluorite structure with melting point $2400^{\circ} \mathrm{C}$ somewhat lower than $\mathrm{UO}_{2} 2865^{\circ} \mathrm{C}$ ) with additions of oxide particles with limited solubility (e.g., $\mathrm{Al}_{2} \mathrm{O}_{3}$ ) to examine the effects of second phase particle size and volume fraction on the microstructural stability. With the knowledge gained in these studies, similar studies will combine microstructural stability with increased thermal conductivity with the addition of a high thermal conductivity second phase (e.g., $\mathrm{BeO} 280-300 \mathrm{~W} / \mathrm{m} \mathrm{K}$ or $\mathrm{SiC} 80-150 \mathrm{~W} / \mathrm{m} \mathrm{K}$ ).

3. The percolation limit (i.e., the amount of second phase needed to increase thermal conductivity) will be established as a function of volume content and size of the second phase through modeling and experimental studies.

The above mentioned efforts will be part of a detailed R\&D plan and will be accompanied by a conceptual fuel design, fabrication flowsheet description and diagram, neutronics analysis, temperature and power performance, and a used fuel recycle flow scheme including waste streams and description of waste minimization efforts.

\subsubsection{Potential Benefits}

The objective of this project is to develop an advanced $\mathrm{UO}_{2}$ fuel having increased the thermal conductivity, increased toughness and engineered grain boundaries, which will reduce fission gas release. These changes in the fuel properties should allow the reactor to operate at higher power levels, with less fission gas release and larger safety margins. It will potentially allow more energy to be extracted from the fuel since one of its limiting factors, the decrease in thermal conductivity with burn-up, will be removed. It also makes possible the use of higher enrichment fuels and longer burn-up times thus decreasing the total amount of spent fuel per megawatt of electricity. 


\subsubsection{ORNL R\&D Team}

Dan Hollenbach, Pete Pappano, Larry Ott, Ted Besmann, James Klett, Paul Becher, HT Lin, Andy Wereszczak, Ron Ellis, Bob Jubin, Stewart Voit

1. U. B. DERARMENT of ENERGY

Nuclear Energy

\section{Enhanced Thermal Conductivity \& Grain Boundary Engineering of Oxide Fuels}

\section{Objective is to develop a composite $\mathrm{UO}_{2}$ fuel for Existing and Advanced Reactors}

- Easily incorporated into existing manufacturing processes

- Increase and stabilize the bulk Thermal Conductivity (TC) as a function of burnup

- Currently thermal canductivity is very low and decreases with bumup

- Allows for higher power densities and higher burnups (more GWd/MTU)

\section{$\mathrm{UO}_{2} /$ Fiber Composites}

- Long thin fibers of material will be added to $\mathrm{UO}_{2}$ prior to compressing and sintering pellets

- High thermal conductivity (-100 times greater the UO, ar higher)

- Lower neuton cooss section, high melting temperature, and chemically non-reactive with UO,

- Fb ars compose less than $5 \%$ of total compact volume (pellet $>95 \%$ UO, by wolume)

\section{Grain boundary Engineering}

- Pin UO $\mathrm{O}_{2}$ grain boundaries to prevent exaggerated grain growth

- Carbide-based whiskers or chopped fibers exhibited very high thermal conductivity

- Establish Percolation limit for the onset of rapid Thermal Conductivity increase

- Examine the effects of $2^{\text {nd }}$ phase aspect ratio and volume fraction on microstructure stability

\section{nesearch Plan}

- Create multiple composite types using different materials and volume percents

- Irradiate material in reactor while monitoring temperature to determine effect of burnup on TC 


\subsection{Rank 9: High Burn-Up Ceramic Composite Nuclear Fuels}

Concept Lead: Kurt Sickafus (LANL)

\subsubsection{Executive Summary}

We propose to develop high burn-up ceramic nuclear fuels for application in: (1) conventional light-water reactors (LWRs); and (2) fast reactors (FRs). Our fuel designs will be based on composite (multi-phase) ceramics. In the initial studies, the fissile phase in these composites will be uranium dioxide ( $\mathrm{UO}_{2}$ ) or a mixed oxide containing $U$ and one or more transuranic (TRU) elements. Other fissionable phases, including carbides, nitrides, oxycarbides and oxynitrides will be considered later.

The innovation in our concept is that one or more non-fissile phases will be incorporated with the $\mathrm{UO}_{2}$ or TRU-bearing phases, such that all phases possess small grain sizes ( $\sim \mu \mathrm{m}$ or less). These additional phases will assume several roles, including: (1) gettering sites for high-yield fission products; (2) enhancing thermal conductivity; (3) buffer phases for oxygen potential control; (4) arresting undesirable

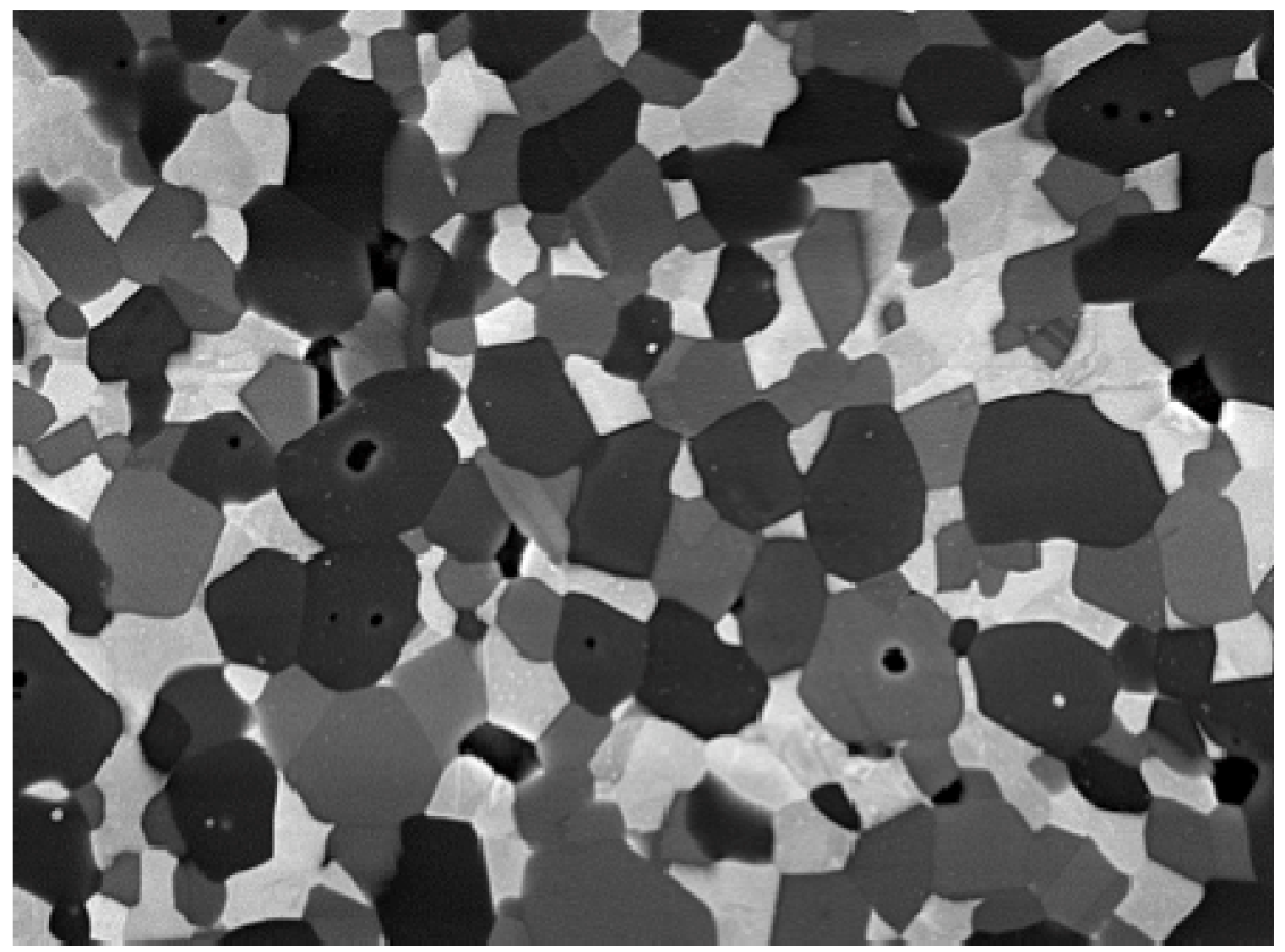

Figure 15. An illustrative example of a multi-phase ceramic microstructure with finely-dispersed grains of various oxide phases (photo courtesy of M. Mecartney).

microstructural evolution, such as swelling, thermal and radiation-enhanced creep, elemental partitioning, radial cracking and the formation of central voids; and (5) reducing undesirable fuelclad interactions. If the added phases in our composite fuels function according to design, we 
anticipate that we will achieve significant advances toward very high burn-up fuels, compared to the performance of conventional $\mathrm{UO}_{2}$ and $\mathrm{MOX}$ fuels. The reason that our concept will improve fuel performance is that non-fissile phases dispersed within the actinide oxide at the start of irradiation, will offer the means to control fission product accumulation and to arrest or delay undesirable microstructural evolution (grain growth, texture development, swelling, cracking) and chemical interactions with the cladding. The composite microstructure will simultaneously promote a physical and chemical partitioning between residual actinides (An) and fission products (FPs) that can provide novel recycle and waste disposition options for the used fuel.

R\&D Team: LANL: Overall lead, Synthesis, Fabrication, Properties, Neutronics, Separations, Safeguards ORNL: Thermodynamics, Synthesis INL: Performance University of California Irvine:

Synthesis, Fabrication, Properties University of Nevada - Las Vegas: Separations, Synthesis University of Colorado - Synthesis, Fabrication, Properties

Program Description. We propose a comprehensive research program to establish the viability of a fuel cycle based on advanced ceramic composite nuclear fuels. This program will include the following tasks:

(1) A theoretical thermodynamics task designed to inform the experimental projects on equilibrium properties of assemblages of multiple ceramic phases (including temperaturecomposition ( $T-C)$ phase diagrams, impurity solubility, oxygen potentials, etc.).

(2) A multi-faceted synthesis and fabrication task designed to find viable methods to produce prototype, multi-phase ceramic fuel samples, primarily via aqueous processing routes, so as to mitigate dry-processing (powder) problems such as dust generation and excessive fabrication losses.

(3) A high-temperature mechanical and irradiation testing effort designed to examine nonequilibrium properties such as microstructural stability, macroscopic durability, lack of phase intermixing and the functionality of minor phases, including FP gettering, thermal conductivity enhancement, and oxygen buffering.

(4) A theoretical neutronics task to examine the feasibility of using multi-phase ceramic fuel in a conventional LWR or FR reactor core, with an emphasis on optimization of fuel structure, composition, and enrichment, necessary to achieve acceptable in-core performance.

(5) A separations and waste disposition task with a goal to examine possible separations strategies that ease the burdens associated with efficient removal of a large portion of the FPs. 2

(6) Evaluation of potential safeguards and non-proliferation advantages of recycle options using these novel fuel forms. For tasks (4)-(6), collaborative efforts (and funding) appear likely with the appropriate FCR\&D Campaigns.

Approach. We begin this program with an exploratory phase (Phase I, 6-9 months) in which each task team will examine a variety of fuel forms, fabrication routes, reactor core configurations, etc., and identify the key problems that must be solved in order to implement an advanced composite ceramic fuel in a real fuel cycle. Phase I will lead to a demonstration phase (Phase II), in which all of the tasks will focus on the most promising composite fuel systems, which will be down-selected from the research results of Phase I.

In Phase I, coordinated efforts among the team members in the six institutions will lead to a recommendation of selected fissile and non-fissile phases for a multi-year, two-tiered, theory 
and experiment-based approach in Phase II. The two-tier approach refers to parallel investigations of surrogate fuel forms (depleted $U$ ) and actual fuel forms containing $U$ and TRU. The use of surrogate fuel provides a rapid way to evaluate fabrication techniques, characterization of microstructure, and the behavior of FPs within the composite fuel forms. Phase I activities will include the following:

(1) Thermodynamics and kinetics. We will assess thermodynamic and kinetic factors in ceramic composite fuel designs. This will involve thermodynamics modeling ( $T$ - $C$ diagrams, chemical and oxygen potentials) of multi-phase oxides (or carbides, nitrides, oxycarbides and oxynitrides)

(2) Fuel Fabrication. We will assess possible synthesis routes to multi-phase ceramics, with an emphasis on aqueous processing (benefits include reduction of process losses), including: (i) conventional co-precipitation methods; (ii) direct precipitation from nitrates in phosphoric acid; (iii) internal gelation; and (iv) polymer-derived bulk ceramics (PDBC).

(3) Thermal, Mechanical \& Irradiation Effects. We will evaluate methods for testing and characterizing composite microstructural evolution and durability in extreme environments (high radiation dose and temperature). We will consider the following issues: (i) inter-phase reactions and grain growth; (ii) changes in mechanical properties such as creep, hardness, and fracture toughness; and (iii) radiation-induced microstructural evolution and FP incorporation.

(4) Neutronics. We will initiate particle (neutron) transport calculations on multi-phase fuel forms to assure adequate performance (i.e., reactivity) in a reactor. The results of the transport calculations will be coupled with thermal analyses and/or burn-up calculations for additional insight. We will also perform transmutation calculations (An and FP inventories as a function of burn-up).

(5) Separations and Waste. We will perform an initial assessment of potential advantages of An recycle and FP disposal using these composite fuel forms. (6) Safeguards and Non-

Proliferation. We will identify the key issues associated with developing a safe and secure fuel cycle involving advanced ceramic nuclear fuel forms. 


\section{Composite Nuclear Fuels}

Dispersion nuclear fuel concept : one or more non-fissile phases are incorporated with the fissile $\mathrm{UO}_{2}$ or TRU-bearing phases.

- Role of non-fissile phases: enhancing thermal conductivity, gettering fission products, arresting microstructural evolution, etc.

\section{- Deliverables for FY10}

- Selection of prospective candidates for the fissile and non -fissile phases that offer a non-aqueous separation strategy adaptable to modified open cycle

- R\&D plan for fabrication, characterization and recycling

\section{- Key areas for FY11 and beyond}

- Compare and contrast various fabrication methods

- Ion irradiation and characterization of model samples

- FP segregation testing in HFIR and/or ATR
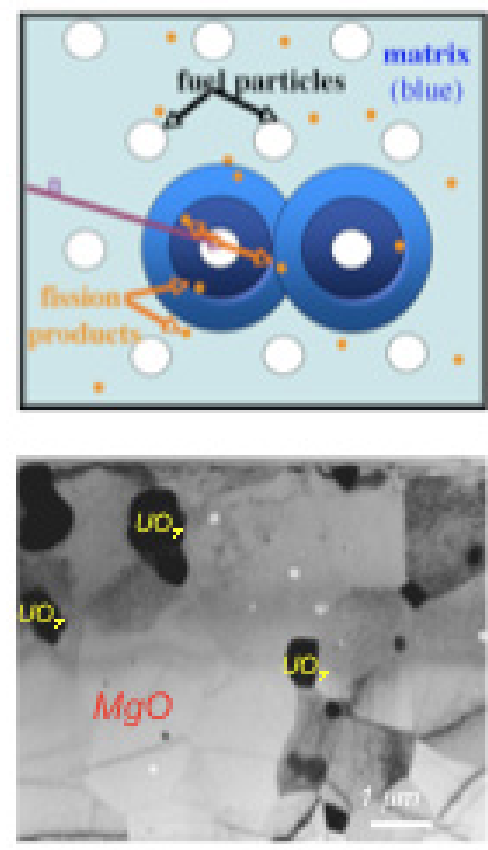

12

Figure 16. Graphical summary of ceramic composite nuclear fuel concept. 


\subsection{Special Selection: Thorium-Based Fuel Options for Thermal and Fast Reactors}

Multiple proposals were received proposing the use of thorium based fuel. Because this presents a fundamentally different approach to the nuclear fuel cycle for the United States and the implementation of a thorium fuel cycle is not fully understood, a nominal amount of funding has been allocated to study the use of thorium as a fuel. The Brookhaven National Laboratory has been tasked to provide a study to inform the Advanced Fuels Campaign on the use of thorium. BNL is tasked to coordinate and consider the topics proposed in the additional thorium proposals. Brookhaven National Laboratory was tasked with this responsibility because BNL was a proposer or co-sponsor of all Thorium proposals.

\subsubsection{Description of Concept/Innovative Aspects}

Thorium has been considered as an option to uranium-based fuel since the earliest days of the nuclear industry, initially based on considerations of resource utilization (thorium is approximately three times more plentiful than uranium), and more recently as a result of concerns about proliferation and waste management. While operating experience with thoriumbased fuels in the US has been limited, many design studies have been performed in the US and internationally examining options for the utilization of thorium designed to demonstrate its anticipated benefits. These include reduced production of plutonium and higher actinides and potential improvements in reactor performance, safety, and waste characteristics. Since these goals are major objectives of the Advanced Fuels Campaign of the Fuel Cycle Research and Development (FCRD) program, and there has been no consideration of thorium-based fuels in the US fuel cycle programs over the past decade, it is proposed to examine thorium-based fuel options for implementation in both thermal light water reactors (LWRs) and fast spectrum reactors (FSRs).

Practical implementation of advanced/innovative fuels is constrained by the characteristics of "practical" reactors, operating experience, and the relative risk versus the potential benefits. The utilities which operate commercial reactors must be convinced of a tangible benefit, and have reasonable assurance that the concept will be licensed by the USNRC. With these considerations in mind, we propose to consider two "scenarios": (1) utilization in current design LWRs and FSRs with relatively conventional fuel/target characteristics (e.g., oxide fuel, cylindrical pelletclad geometry), but thorium-based; and (2) unconventional fuel characteristics that include thorium (e.g., metallic fuel in LWRs). Issues associated with both once-through and re-cycle options will be addressed (e.g., reprocessing).

\subsubsection{Potential Benefits}

Numerous studies of thorium-based fuels in combination with U-233, U-235 and plutonium/minor actinides (TRU) to supply the required fissile inventory have confirmed some of the expected benefits relative to fuels based on uranium. These have included seed-blanket options in PWRs which demonstrated reduced plutonium production, degraded plutonium isotopics with respect to potential use in a weapon (high heating from $\mathrm{Pu}-238$ and spontaneous neutron production from $\mathrm{Pu}-238, \mathrm{Pu}-240$ and $\mathrm{Pu}-242$ ), and reduced waste per GWe-yr in oncethrough cycles relative to conventional uranium-based fuels. The ability to more efficiently burn plutonium than in conventional U-Pu MOX fuel in LWRs has also been demonstrated in several studies. In addition, some of the physical properties of thorium-based fuels in both oxide and metallic forms which affect reactor performance are better than those for uranium-based fuels as shown in Table-1, with higher margins to fuel melting, and higher thermal conductivity thereby 
reducing fuel temperature and stored energy. As a result, thorium-based fuels should be fundamentally capable of higher burnup than uranium fuels. Fuel performance parameters such as burnup potential and safety during accident scenarios which depend on potential chemical and mechanical interactions with the cladding and the coolant will also be addressed. Prof. Tulenko was Head of Nuclear Fuel Engineering at B\&W when PIE was performed on the Thoria-Urania core irradiated at Indian Point-1. These examinations revealed very low fuel swelling, very low fission gas release, and no fuel-cladding mechanical interaction-much better performance than conventional $\mathrm{UO}_{2}$ pellet fuel

An issue that must be addressed with thorium-based fuels is the proliferation risk associated with the bred U-233. If this is a significant concern, it is most effectively addressed by adding sufficient uranium to the thorium in the initial fuel composition so that all the U-233 (and any U235 ) is diluted with U-238 in-situ such that SNM can only be obtained with isotopic separation. While this greatly reduces proliferation concerns, the addition of uranium leads to the creation of more TRU, diminishing the difference between uranium-based and thorium-based fuel systems in this regard.

Table-1 Selected Properties of Uranium and Thorium Based Fuels

\begin{tabular}{|l|l|l|}
\hline & \multicolumn{1}{|c|}{ Uranium } & \multicolumn{1}{c|}{ Thorium } \\
\hline $\begin{array}{l}\text { Oxide: } \\
\text { thermal conductivity }\end{array}$ & \multicolumn{1}{|c|}{$\begin{array}{l}\text { 2.5 W/m- }{ }^{\circ} \mathrm{C}\left(1700^{\circ} \mathrm{C}\right) \\
\text { melting temperature }\end{array}$} & $\begin{array}{l}3.0 \mathrm{~W} / \mathrm{m}-{ }^{\circ} \mathrm{C}\left(1700^{\circ} \mathrm{C}\right) \\
3300^{\circ} \mathrm{C}\end{array}$ \\
\hline $\begin{array}{l}\text { Metallic: } \\
\text { thermal conductivity }\end{array}$ & & \\
minimum solidus & $360^{\circ} \mathrm{C} \mathrm{W} / \mathrm{m}-{ }^{\circ} \mathrm{C}\left(800^{\circ} \mathrm{C}\right)$ & $45 \mathrm{~W} / \mathrm{m}-{ }^{\circ} \mathrm{C}\left(800^{\circ} \mathrm{C}\right)$ \\
coefficient of thermal expansion & $1135^{\circ} \mathrm{C}(\mathrm{U}-\mathrm{Zr})$ & $1350^{\circ} \mathrm{C}(\mathrm{Th}-\mathrm{Zr})$ \\
$13.9 \times 10^{-6} \mathrm{~K}^{-1}$ & $11.0 \times 10^{-6} \mathrm{~K}^{-1}$ \\
\hline
\end{tabular}

\subsubsection{Research and Development Team}

The R\&D team will consist of:

Brookhaven National Laboratory (BNL): M. Todosow (PI)

Idaho National Laboratory (INL): S. Hayes (POC)

Los Alamos National Laboratory (LANL): H. Trellue (POC)

University of Florida (UF): J. Tulenko (POC)

Lightbridge Corp. (LTBR): M. Montgomery (POC)

Requested Budget: $\$ 500 \mathrm{~K}$

Initial Concept Development: BNL and LANL will focus on developing reactor concepts utilizing thorium-based fuel and evaluating expected reactor performance and safety. These studies will leverage the experience developed over many years evaluating such concepts under various programs (NERI, AFCI, etc.). Other aspects of the fuel cycle (e.g., mining, proliferation and waste characteristics) will also be considered.

Fuel Development: Review of previous work in thorium-based fuel fabrication, characterization, and performance, and development of R\&D plans and prototype testing for implementation in LWRs and FSRs will be performed by INL (focus on metallic fuel), LANL and UF (focus on oxide fuel). LANL 
will also address fuel performance modeling for thorium-based fuels. LTBR will review and comment on fuel technology options defined in this effort based on its extensive experience with its seed-and-blanket fuel design (i.e., metal seed and thorium-uranium oxide blanket) for Russian VVER-1000 reactors and Western PWRs.

\subsubsection{Thorium oxide fuel Concept Lead: Holly Trellue (LANL) Description}

The thorium (Th) fuel cycle offers advantages over the traditional low-enriched uranium (LEU) and mixed oxide (MOX) fuel cycles in existing commercial Light Water Reactors (LWRs). Thorium fuel was irradiated in the Shippingport, Indian Point, and Ft. St. Vrain reactors in United States in the past but has not been as actively explored as the uranium fuel cycle. High burnup thorium fuel placed in today's commercial LWRs could extend the length of each cycle and/or reactor lifetime. Additionally, depleted uranium could be replaced with thorium in a fast system to increase the consumption rate of actinides (particularly plutonium, which builds in from $238 \mathrm{U}$ ). Thorium is not fissile itself; $232 \mathrm{Th}$ is a fertile isotope, which means that following irradiation, it produces a fissile isotope $(233 \mathrm{U})$. Thus, a LWR burning thorium fuel would have to be dually-loaded with another fissile isotope (either LEU or plutonium $(\mathrm{Pu})$ ) to achieve sufficient reactivity.

\subsubsection{Potential Benefits}

1) Less plutonium builds up in Th/LEU than in LEU fuel and more net plutonium can be destroyed in $\mathrm{Th} / \mathrm{Pu}$ than in MOX fuel because there is less $238 \mathrm{U}$ present.

2) Thorium is three to four times more abundant than uranium, offering economic incentives both from mining and from reduced enrichment needs.

3) Thorium is a more stable fuel material chemically than LEU, so it may withstand higher burnups, particularly if surrounded by less oxidizing cladding than currently used.

4) The materials attractiveness of plutonium in Th/Pu in LWRs at high burnups ( $90 \mathrm{MWd} / \mathrm{kgHM})$ is lower than in MOX at currently achievable burnups ( $\sim 60 \mathrm{MWd} / \mathrm{kgHM}){ }^{\mathrm{a}}$

\section{High Burnup Capability}

The high thermal conductivity and low fission gas release of thorium fuels has potential for higher linear power, longer cycles, less waste, and higher discharge burn-up than $\mathrm{UO}_{2}$ and traditional MOX. The higher thermal conductivity and melting point of thorium can reduce the temperature gradient, mitigate some of the fuel cracking and oxygen vacancy issues, minimize densification and creep, and reduce fuel/cladding reactions. An innovative idea is to explore silicon carbide fiber reinforced silicon carbide composites $(\mathrm{SiC} / \mathrm{SiC})$ and/or other materials as a transformational fuel cladding that may withstand higher burnups than zircaloy.

\section{Low Fabrication Losses}

Based upon MOX fuel fabrication experience in Europe and Japan and innovative research at U.S. universities, multiple process improvements are available to achieve reductions in fabrication losses. Examples include pre-reaction of constituent via wet or dry processing, incorporation of sintering aids, and use of alternative sintering techniques that employ shorter process times and lower temperatures.

\section{Ability to Transmute Transuranics}

$\mathrm{Th} / \mathrm{Pu}$ fuel destroys Pu more efficiently than traditional MOX fuel (studies have shown that up to two times more plutonium is destroyed). 1 The use of thorium instead of depleted uranium mixed with

a. H. R. Trellue, "Neutronics and Material Attractiveness Calculations for PWR Th Systems," LA-UR-10-00027. 
transuranics (TRU) in a fast reactor should similarly exhibit superior consumption rates to help destroy used nuclear fuel.

\section{Fuel Cycle Impacts}

The main impacts of irradiating thorium in existing once-through LWRs to the nuclear fuel cycle would be to the mining/milling and fabrication processes. Irradiation of Th fuel should behave similarly to that of MOX fuel and the composition of used nuclear fuel would also change compared to LEU. If high burnup in thorium fuels is achievable, the amount of used nuclear fuel produced would be significantly reduced per unit power generated. Closed Th/TRU fuel cycles in either a thermal or fast spectrum would allow destruction of a large portion of existing irradiated fuel and more significant fuel cycle impacts.

\subsubsection{R\&D Team}

LANL: Ceramic Processing and Properties, Neutronics, Separations, Safeguards

$B N L$ : Neutronics, Performance

\subsubsection{Proposed Work}

\section{Neutronics and Fuel Cycle Impacts (LANL and BNL)}

Neutronic analyses are required to demonstrate the quantity and composition of material that should go into a fuel in a particular system. Neutronic analyses on thorium-based fuels have been and will continue to be performed using pin-cell, assembly, and partial core models in MCNP and other codes. These results will feed into burnup and thermal calculations such as temperature and power performance of the system. Neutronic studies will show what burnups are required to achieve reduced material attractiveness in the product and may analyze other fuel types, including oxides, metals, and possibly nitrides or carbides for comparison. Changes to the fuel cycle flow diagram for thorium oxide will also be outlined.

\section{Thorium Oxide Fuel Fabrication and Modeling (LANL)}

LANL has expertise in ceramic fuel fabrication and separations and has successfully achieved high density $\mathrm{ThO}_{2}-\mathrm{CeO}_{2}$ (surrogate for $\mathrm{ThO}_{2}-\mathrm{PuO}_{2}$ ) fuel pellets with various compositions of $\mathrm{ThO}_{2}$ at $94 \%$ to 95\% theoretical density (Fig. 1). Using conventional dry ball milling, these fuel pellets have a uniform single phase and micron-sized pores. LANL will examine using an innovative nanoparticle fissile species concept for future fabrication which can reduce the sintering temperature (which is higher for Th- than traditional $\mathrm{Pu}-\mathrm{MOX}$ ). In addition, nanoparticles can result in fine microstructure with uniform fine pore distribution (Fig. 2). Alternate fabrication techniques, such as extrusion, to will be explored targeting net shape pellet forming. The most critical aspects will be to optimize the fabrication in order to establish reliable microstructural and dimensional control of the product while minimizing process losses.

Predicting the interplay of thermal, chemical and mechanical phenomena in actinide oxide fuel elements is challenging. More research needs to be performed on thorium-based fuels to address the stoichiometry, thermal transport, gradient of oxygen concentration as a function of temperature, microstructure effects, and other behaviors.2 Proposed work involves investigation of the different fabrication processes required for $\mathrm{Th} / \mathrm{Pu}, \mathrm{Th} / \mathrm{U}$, and $\mathrm{Th} / \mathrm{U} / \mathrm{Pu}$ oxide fuels. Preliminary results from both fuel modeling and fabrication efforts will contribute to a detailed conceptual fuel design and fabrication flow diagram. Research and development plans for both fuel and cladding prototype testing and elucidation of technology gaps will be produced. 2. M. Stan and P. Cristea, J. Nucl. Mater. 344 (2005) 213. 


\section{Appendix A: Call for Proposals}

\section{Innovative Transmutation Fuels Concepts Call For White Papers - Deadline: Jan 15, 2010 DOE Fuel Cycle R\&D}

As part of the Fuel Cycle R\&D longer-term, science based focus, there is a desire to promote the generation of new ideas and foster exploration of transformational technology options. The purpose of this call for white papers is to generate a collection of innovative transmutation fuels concepts. A balanced science-based R\&D approach will include both performance enhancement and investigation of evolutionary concepts. The FCRD Fuels Campaign will pursue this balanced approach.

The FCRD Fuels Campaign is seeking innovative fuel and target design concepts that have the ability to meet the following grand challenge goals of high burnup performance and low loss fabrication. These concepts are not strictly limited to fast spectrum systems but successful concepts must address:

1) High burnup capability for the concept ( $400 \mathrm{GWd} / \mathrm{MT}$ or greater for fast spectrum systems with no cladding breach, or multifold increases in performance for LWR/thermal fuels, as examples)

2) Low fabrication losses (i.e. reduction of need to dispose of heel and scrap wastes, $<0.1 \%$ )

3) Ability to transmute transuranics

4) Consider fuel cycle impacts.

The white paper should include three elements:

1) A preliminary description of the concept and why it is innovative (e.g., disturbs the status quo).

2) Potential benefits of the concept and how the concept improves fuel performance. (Not all innovative or transformational ideas will yield improved performance.)

3) Identification of the R\&D team. Explain who will conduct initial concept development and rough assessment of needed R\&D; multi-Lab or University inclusive teams are encouraged, but not required.

There is $\$ 1 \mathrm{M}$ available for award(s) in FY-2010. It is expected that 2 to 3 individual concepts will be funded in the range of $\$ 300$ to $500 \mathrm{~K}$ each and will be expected to deliver a detailed conceptual fuel design, detailed process fabrication flow diagram, detailed neutronic analysis, detailed temperature and power performance, and detailed recycle flow diagram, and detailed research and development plan to elucidate technology gaps by September 30, 2010.

The complete set of white papers will be reviewed and prioritized in February. Please be prepared to participate in a February 2010 workshop where you or a representative will present the white paper concept(s) in oral presentation format for question and answer by the selection committee. This workshop location has not been established but is expected to be in a central location. After the workshop, topics will be selected for additional funding.

\begin{tabular}{|l|l|}
\hline \multicolumn{2}{|l}{ Submission Requirements } \\
\hline Deadline & January 15, 2010 \\
\hline Method & E-Mail submissions to Lori Braase, lori.braase ginl.gov \\
\hline Paper Requirements & $\begin{array}{l}\text { 2-Pages or less, } 12 \text { point - single spaced } \\
\text { Word Document Format } \\
\text { Three (3) white papers from each Laboratory (maximum) }\end{array}$ \\
\hline Oral Presentation & $\begin{array}{l}\text { February 2010 Workshop (Location TBD) } \\
\text { Powerpoint format presentations }\end{array}$ \\
\hline
\end{tabular}

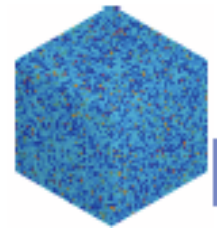

Please submit your white papers to: Lori Braase, loribraase ainl.gov, 208-526-7763 and cc: Jon Carmack, 208-526-6360, joncarmack/äinl.gov and Kemal Pasamehmetoglu, 208-526-5305, kemal.pasamehmetoglu $/$ inl.gov. Please feel free to contact one of the above with questions. 


\section{Appendix B: Review Committee Charter \\ Advanced Fuels Innovative Concept Proposals Review Committee Charter and Review Process}

\section{Scope}

The FCRD Advanced Fuels Campaign is seeking innovative fuel and target design concepts that have the ability to meet the grand challenge goals in terms of achieving very high burnups and enhancing the fabrication efficiencies as indicated in the original call for whitepapers. The advanced fuels campaign issued the call for white papers for innovative transmutation fuel concepts on October 31 . The call for whitepapers is provided as an attachment to this charter. A review of the proposed concepts is being performed by an independent review committee, which will report its findings and recommendations to the Advanced Fuels National Technical Director at the conclusion of the review. This is not a consensus report but a report by each review committee member.

Each committee member will provide his/her ranking of the proposals as high, medium or low:

High $(7,8,9)$ - a potential game changer that should be funded if at all possible

Medium $(4,5,6)$ - very innovative proposal that should be considered for funding in future years

Low $(1,2,3)$ - should not be considered for funding at this time

The criteria that the committee should consider in their ranking should include (but not limited to) the following:

1. Potential impact if successful and estimate of time to success

2. Burnup and performance capability

3. Efficient fabrication capability

4. Transmutation Capability and Fuel Cycle Impact

5. Identification of needed $R \& D$

6. R\&D Team capability

A questionnaire that includes the above items will be distributed to the review committee members before the beginning of the oral presentations.

\section{Review Process}

The process includes the review of the white papers and discussions during oral presentations by the PIs of the white papers.

- White papers from the National Laboratories proposing innovative fuel concepts will be collected and distributed to the review committee and meeting observers by the Advanced Fuels Campaign National Technical Director;

- A review meeting will be held where the concepts will be presented to and discussed with the review team and the observers by the concept proponents;

- During the review only the review committee members and observers will be allowed to ask questions to the presenters; 
- The review committee members will be asked to fill out a questionnaire at the end of each presentation and submit them to the review committee chair-person

- At the conclusion of the meeting, the review committee will provide a report to the Advanced Fuels campaign Director;

- Evaluating the review committee report the Campaign Director and The Federal Campaign manager will provide their recommendations for scope and funding to the FCRD Program Director.

\section{Deliverable}

A summary report that summarizes the committee recommendations of each committee member and salient highlights of the discussions during the review meeting will be submitted to the Campaign Director the day after the review meeting is completed. The summary report is not a consensus report but it would provide the general observations made during the review meeting and the questionnaires filled by the individual reviewers. The questionnaires filled by the individual review members will be attached to the summary report.

\section{Review Committee Members}

Michael Cappiello, (FCRD TIO) (Chairperson)

Dave Alberstein, (retired LANL)

Richard Hobbins, (retired INL)

Dave Copeland, (retired ORNL)

Madeline Feltus (DOE-NE)

Robert Hill (ANL, FCRD Reactors Campaign Director)

Leon Walters (retired ANL)

\section{Meeting Observers}

Richard Black (DOE-NE)

Jon Carmack (INL, FCRD Advanced Fuels Deputy Campaign Director)

Frank Goldner (DOE-NE)

John Herczeg (DOE-NE)

John Kelly (SNL)

Stuart Maloy (LANL, FCRD Advanced Fuels Deputy Campaign Director)

Kemal Pasamehmetoglu (INL, FCRD Advanced Fuels Campaign Director)

Rich Reister (DOE-NE)

Terry Todd (INL, FCRD Separations Campaign Director)

Rob Versluis (DOE-NE)

Bradley Williams (DOE-NE)

The meeting observers will be allowed to ask questions and participate in the discussions during the meeting. The observers may choose to submit written comments. The review committee chairman will decide how those comments are reflected in the final report. 